\title{
WestVirginiaUniversity
}

THE RESEARCH REPOSITORY @ WVU

Graduate Theses, Dissertations, and Problem Reports

2007

\section{College students' perceptions of dialects}

\author{
Leigh Smitley \\ West Virginia University
}

Follow this and additional works at: https://researchrepository.wvu.edu/etd

\section{Recommended Citation}

Smitley, Leigh, "College students' perceptions of dialects" (2007). Graduate Theses, Dissertations, and Problem Reports. 2540.

https://researchrepository.wvu.edu/etd/2540

This Thesis is protected by copyright and/or related rights. It has been brought to you by the The Research Repository @ WVU with permission from the rights-holder(s). You are free to use this Thesis in any way that is permitted by the copyright and related rights legislation that applies to your use. For other uses you must obtain permission from the rights-holder(s) directly, unless additional rights are indicated by a Creative Commons license in the record and/ or on the work itself. This Thesis has been accepted for inclusion in WVU Graduate Theses, Dissertations, and Problem Reports collection by an authorized administrator of The Research Repository @ WVU. For more information, please contact researchrepository@mail.wvu.edu. 
College Students' Perceptions of Dialects

\author{
Leigh Smitley, B.S.
}

Thesis Submitted to the College of Human Resources and Education at West Virginia University

in partial fulfillment of the requirements

for the degree of

Master of Science

in

Speech Pathology

Carolyn P. Atkins, Ed.D., CCC-SLP, Chair

Lynn R. Cartwright, Ed.D., CCC-SLP

Cheryl L. Prichard, Ed.D., CCC-SLP

Dennis M. Ruscello, Ph.D., CCC-SLP

Mary Ellen Tekieli Koay, Ph.D., CCC-SLP

Department of Speech Pathology and Audiology

Morgantown, West Virginia

2007

Keywords: Dialect; Stereotypes; African-American Dialect; Appalachian-American Dialect; Eastern-American Dialect; General-American Dialect; Gender 


\author{
Abstract \\ College Students' Perceptions of Dialects \\ Leigh Smitley, B.S.
}

The purpose of this investigation was to determine college students' perceptions of their own dialects and 4 specific dialects common to the English language. To determine this, the investigator developed a 3-part survey (Appendices H, I, J). On Part I, respondents completed identifying information. On Part II, they rated 9 general Likert Scale items related to dialect. On Part III, they completed the same semantic differential scale for speakers who represented 4 different dialects: Appalachian-American, EasternAmerican, General-American, and African-American. There were 2 speakers for each dialect, i.e., 1 male and 1 female.

On Part I, respondents who completed a 3-part survey included 143 undergraduate students at West Virginia University; 53.1\% were between the ages of 19 and 20 years old. The majority (74.8\%) was female and Caucasian (96.5\%). In addition, the majority (46.2\%) felt they spoke with a dialect while $31.8 \%$ identified themselves as speaking with a General-American dialect.

On Part II, respondents indicated personal satisfaction with the way they speak. They also were comfortable speaking in formal and informal settings despite their dialects and did not feel others stereotyped them negatively because of their dialects.

On Part III of this investigation respondents assigned the highest mean to the General-American male (3.90); followed by the African-American female (3.86); the General-American female (3.72); the Appalachian-American female (3.55); the Eastern- 
American female (3.46); the Appalachian-American male (3.35); the Eastern-American male (2.91); and the African-American male (2.88). Overall means for each of the dialects reveal that respondents rated General-American dialect speakers most positively with a mean of 3.81, followed by Appalachian-American dialect speakers (3.45), African-American dialect speakers (3.37), and Eastern-American dialect speakers (3.19). Appalachian-American speakers are perceived as approachable, mature, friendly, humble, stable, and even-tempered, with the female being more positively stereotyped than the male. Eastern-American speakers are perceived as mature, attractive, stable, and even-tempered, with the female being more positively stereotyped than the male. General-American speakers are perceived as intelligent, approachable, mature, motivated, powerful, attractive, friendly, stable, and even-tempered, with the male being more positively stereotyped than the female. African-American speakers are perceived as approachable, friendly, and even-tempered, with the female being more positively stereotyped than the male.

The findings suggest individuals do indeed stereotype others, whether positively or negatively, based on the way in which others speak. For the most part, the stereotypes identified in this study supported the findings identified in a review of the literature. The results of this investigation also supported Robinson's (1996) research findings in which speakers of Non-General-American English were thought to be less educated than speakers of General-American English. This study also was in agreement with Mulac (1976) who found that different stereotypes are associated with different dialects.

Overall, female speakers are perceived as approachable, mature, motivated, powerful, attractive, friendly, stable, and even-tempered, with the General-American 
dialect being most positively stereotyped. Male speakers are perceived as eventempered, with the General-American dialect being most positively stereotyped. 


\section{Table of Contents}

$\begin{array}{ll}\text { Abstract } & \text { ii }- \text { iv }\end{array}$

$\begin{array}{lr}\text { Chapter } 1 \text { - Introduction } & 1 \text { - } 11\end{array}$

I. Statement of the Problem 1

A. Dialectal Characteristics and Stereotypes: Appalachian-American Dialect 2

B. Dialectal Characteristics and Stereotypes: Eastern-American Dialect 4

C. Dialectal Characteristics and Stereotypes: General-American Dialect 4

D. Dialectal Characteristics and Stereotypes: African-American Dialect 5

$\begin{array}{ll}\text { II. } & \text { Existing Research }\end{array}$

$\begin{array}{ll}\text { III. Hypothesis } & 10\end{array}$

$\begin{array}{lr}\text { Chapter 2 - Methods } & 12-20\end{array}$

$\begin{array}{ll}\text { I. Participants } & 12\end{array}$

II. Instrument 12

$\begin{array}{ll}\text { III. } & \text { Procedure }\end{array}$

$\begin{array}{ll}\text { Chapter } 3 \text { - Results } & 21 \text { - } 32\end{array}$

I. Identifying Information - Results of Part I $\quad 21$

II. Likert Scale - Results of Part II $\quad 22$

III. Semantic Differential Scale - Results of Part III 23

A. Appalachian-American Dialect Results - Part III 23

B. Eastern-American Dialect Results - Part III 24

C. General-American Dialect Results - Part III 24

D. African-American Dialect Results - Part III 25

IV. Research Question Results 25 
V. Inter-Dialectal Comparison Results 28

A. Appalachian-American Dialect Female v. Male Comparison 28

B. Eastern-American Dialect Female v. Male Comparison 28

C. General-American Dialect Female v. Male Comparison 29

D. African-American Dialect Female v. Male Comparison 29

$\begin{array}{ll}\text { VI. Gender Comparison } & 30\end{array}$

A. Female Speaker Comparison $\quad 30$

B. Male Speaker Comparison 30

VII. Overall Dialect Ratings 31

$\begin{array}{ll}\text { Chapter } 4 \text { - Discussion } & 33-35\end{array}$

$\begin{array}{lll}\text { I. Summary } & 33\end{array}$

II. Conclusions 33

$\begin{array}{lll}\text { III. Limitations } & 35\end{array}$

IV. Clinical Applications 36

$\begin{array}{lll}\text { V. Suggestions for Future Research } & 37\end{array}$

References

A. Script for Recording 43

B. Cookie Theft Picture 44

C. The Rainbow Passage Paragraph 45

$\begin{array}{ll}\text { D. Idioms } & 46\end{array}$

E. Validity Check Test Form 47

F. Cover Letter for Instrument 48

G. Part I of Instrument 49 
H. Part II of Instrument $\quad 51$

I. Part III of Instrument $\quad 52$

1. Means and Standard Deviations Regarding College Students' Attitudes on Their Own Dialects

2. Means and Standard Deviations for the 10 Bipolar Adjective Pairs for Appalachian-American Female Speaker

3. Means and Standard Deviations for the 10 Bipolar Adjective Pairs for Appalachian-American Male Speaker

4. Means and Standard Deviations for the 10 Bipolar Adjective Pairs for Eastern-American Female Speaker

5. Means and Standard Deviations for the 10 Bipolar Adjective Pairs for Eastern-American Male Speaker

6. Means and Standard Deviations for the 10 Bipolar Adjective Pairs for General-American Female Speaker

7. Means and Standard Deviations for the 10 Bipolar Adjective Pairs for General-American Male Speaker

8. Means and Standard Deviations for the 10 Bipolar Adjective Pairs for African-American Female Speaker

9. Means and Standard Deviations for the 10 Bipolar Adjective Pairs for African-American Male Speaker

10. Correlations between the Respondents' Personal Satisfaction of Own Dialect with Tolerance of Others' Characteristics

11. Overall Mean Dialect Comparisons

12. Correlations between the Years Spent at West Virginia University and the Acceptance of Each Speaker 
6. Female Speaker Comparison

7. Male Speaker Comparison 


\section{Chapter 1 - Introduction}

\section{Statement of the Problem}

According to the American Speech-Language-Hearing Association (ASHA, 2004), dialect "refers to sets of differences, wherever they may occur, that make one English speaker's speech different from one another's" (p. 1). McMenamin (2002) stated that dialect may be any variable difference in the way people pronounce, spell, or form words. The way a person forms sentences, the differences in usage of a given language, and the different meanings given to individual words all contribute to a dialect.

McMenamin (2002) stated that dialect is spoken by subgroups of individuals who are historically, geographically, and/or socially disconnected from the whole. Therefore, it makes perfect sense that there would be some variation in the language between each subgroup of speakers since they are a different set of individuals with common, yet different, factors affecting them. For example, everyone must deal with the weather, but where they live determines if they will be facing a blizzard, a hurricane, or some weather in between.

Because America is considered to be a "melting pot," variations in language are inevitable and the world is diverse because of these variations. According to the 2002 United States Census Bureau, 236,232,000 people living in the United States reported being Caucasian; 38,138,000 reported being African American; 
4,328,000 reported being American Indian or Alaskan Native; 13,087,000 reported being Asian; and 943,000 reported being Native Hawaiian or Pacific Islander. Dialects are neither good nor bad; they are just different. Regardless of the social dialect, the language spoken still maintains the basic systematic features of any language. According to ASHA's position statement on social dialect (1983), all dialects follow a similar structure of "phonology, morphology, syntax, semantics, lexicon, pragmatics, suprasegmental features, and kinesics" (p. 77). This investigation focuses on the noticeable differences, characteristics, and perceptions of a particular set about 4 different subgroups of dialects of the English language: Appalachian-American, Eastern-American, General-American, and African-American dialect. To fully understand dialects and why individuals choose to study this phenomenon, one needs to understand the origin and stereotypes that accompany each dialect.

\section{A. Dialectal Characteristics and Stereotypes: Appalachian-American}

Appalachian-American dialect encompasses an area that is rich in folklore and deep-rooted in the Scots-Irish heritage. The Scots-Irish settled the areas of Pennsylvania, Virginia, North Carolina, Kentucky, Tennessee, Georgia, and West Virginia in the 1700's (Trent, 2004). According to the Appalachian Regional Commission (2005), the Appalachian region includes all or some of the counties in the following states: Alabama, Kentucky, Georgia, Maryland, Mississippi, New York, North Carolina, Ohio, Pennsylvania, South Carolina, Tennessee, Virginia, and West Virginia. The name Appalachia reflects the fact that this area is located in the heart of the Appalachian mountain region. Before modern times, it was very difficult for 
individuals inhabiting these areas to communicate with others outside of their region. In Linguistic Geography of Pennsylvania (2003), the author stated that the Appalachian area is known as the "Gateway to the West" and some outsiders believe that inhabitants of that area never advanced through that "gateway" and took advantage of the ways of the "Western World" (Waller, 2002). This may cause some to believe that Appalachian people are not well educated or lack cultural experience and refinement.

The many regions within this area may also present variations in terms of dialect. Differences are noticed by word choice when describing certain items. A "spigot" is an outside faucet; "Jeet?" is a common question meaning "Did you eat?"; and Mamas know when their babies "look peaked" or sick. The Appalachian area is also known for double negatives, (e.g... "She don't know nothin"”) and dropping the endings from words, (e.g., "slep" instead of "slept"). The Appalachian-American dialect and the associated images are perceived by most listeners as negative. Himes (2004) indicated people believe Appalachians are "nothing but a bunch of uneducated hillbillies brewing up moonshine and getting their dogs ready for hunting season." Dr. Himes, author of Appalachian Studies: History, Culture, and Folkways (2004), explained that "hillbilly" is a term used by individuals outside of Appalachia to insult those who live there. Times are changing and these negative images are often not valid when visiting many Appalachian areas. For example, Morgantown, West Virginia, nestled in the Appalachian Mountains, has been voted among the top 3 "Best Little Cities in the East" since 1999 (Prometheus Books, 2004). In the past 40 years, the negative typecast of Appalachian mountaineers has turned more positive 
because of the aforementioned deep-rooted culture and their great abilities as craftsmen (Waller, 1999).

\section{B. Dialectal Characteristics and Stereotypes: Eastern-American}

Waiting "in line" at the supermarket is a common thing to do unless one lives in New York; then one waits "on line." Eastern Dialect found in the states of New York and New Jersey is very distinctive. Its presence has been popularized on television and in the movies by such characters as "Bugs Bunny, Rosie O'Donnell, and Robert De Niro" (Pangilinan, 2003, p. 1). Individuals speaking this dialect usually do not pronounce the "r," (i.e.,"hahd" for "hard") or add the sound in words that do not have an "r" (i.e., "idear" for "idea"). Another common difference is the " $t$ " or "d" used in place of a "th." For example, it is very common to hear a New Yorker refer to the immediate family as "m^də, fadə, and br^də" as opposed to "mother, father, and brother." They might even be from "Lung Guylin" instead of "Long Island” (Pangilinan, 2003, p. 2). Robert Hendrickson (2003) examined the sayings and characteristics of New Yorkers and focused on the criticism and stereotypical images associated with the dialect. He found that people label New Yorkers, or those who speak with an Eastern dialect, as argumentative and always in a rush. Hendrickson (2003) also found that when it comes to ethnicity, speakers of a New York dialect are almost always labeled as Italians, when in fact there was a large migration of Jewish Americans and other nationalities who chose to settle in New York (Wolfram \& Schillings-Estes, 1998).

\section{Dialectal Characteristics and Stereotypes: General-American}

Reported in a survey entitled Identify the English Accent You Speak with Most Naturally (2004), nearly $30 \%$ of the respondents believe they speak with a General- 
American dialect. Many Americans strive for the General-American dialect because they do not wish to be labeled with the stereotypes associated with certain other dialects. This is evident by the American Speech-Language-Hearing Association's (1983) Social Dialect Position Statement on this topic. Administering clinical services to reduce dialect or services to provide individuals with their "desired level of competency in General-American English” is something speech-language pathologists (SLPs) can carry out under the scope of practice, as long as they are not "jeopardizing the integrity of the client's first dialect" (ASHA, 1983, p. 79). Dialectal speakers often try to conform to the "proper way" of speaking so that these stereotypes, most of which are negative, are not attached to them.

When individuals use their native dialects in informal situations and change to General-American dialect in formal situations, they are code switching. Code switching is the "ability to alternate back and forth between two different languages" (Code Switching, 2004). Code switching can also occur within the same language. Since different situations govern speech patterns, the dialect which people choose to speak depends on who their audience is and the formality of the setting. Examples of GeneralAmerican dialect are abundant when listening to newscasters on major networks and government spokespersons.

\section{Dialectal Characteristics and Stereotypes: African-American}

African-American dialect, also known as African-American Vernacular English (AAVE), continues to be a topic of controversy. Not everyone agrees on the origin of this particular way of speaking and questions concerning its origin remain unanswered. Wolfram (2003) stated that some of the areas that remain under scrutiny include the 
foundation of AAVE's modern, structural aspects, AAVE's course of transformation over the years, and questions about AAVE's original birthplace. McLucas (n.d.) delineates the 2 main hypotheses with regard to AAVE's origin. One, the Dialect Hypothesis, states that AAVE speakers were not taught to speak with correct English dialect. Since slaves were believed to have difficulties when it came to education, they did not receive much formal education; the result was AAVE, or "Bad English." The other, the Creole Hypothesis, is the mixing of general English with many different variations of West African dialects. When slaves where brought to the United States and sent to live wherever they were needed, they were forced to find some way to be able to communicate with each other to survive. The Creole Hypothesis purports that a "pidgin" was formed to help aid in the communication process. According to McLucas (n.d.), a "pidgin is a language composed of 2 or more languages created for the purpose of communication, usually around trade centers, between people who do not speak a common language" (p. 5). Supporters of the Creole theories believe that pidgin has remained, spanned the generations, and evolved into what is AAVE today.

One morphological characteristic of AAVE is the informal use of the verb form "be" (Green, 2000). Some examples of this are presented in Green's Aspectual BEtype Construction in AAE (2000), i.e., "Bruce be singin"' instead of "Bruce sings" (p. 3).

Sidnell (n.d.) offers some differences in vocabulary in his article, African American Vernacular English (Ebonics). In AAVE, "bad" means "really good" and "dig" means "to understand" (Sidnell, n.d.).

McLucas (n.d.) remarked that there is nothing substandard about the AfricanAmerican dialect. Dr. Smith (n.d.), a professor at Indiana University, echoed McLucas's 
statement that there is nothing wrong with "Ebonics." However the stereotypes and prejudices that accompany AAVE are wrong. For example, "uneducated," "loud," "lazy," and "violent" were just few of the negative stereotypes identified by Tan, Fujioka, and Tan (2000).

\section{Existing Research}

Bailey (2003) stated that the past 2 decades have been the most productive time period in the history of the American Dialect Society. Efforts have been made to complete some of the missing links in research on dialects, including completing dialect maps and compiling several dictionaries of dialects. He gave credit to the old programs, but he also supported the new era of dialect research. Bailey (2003) was quoted as saying, "still more research is needed because we have found new ways to answer our questions, both the old ones that activated the founders and the new ones that are now enlarging our understanding of language" (p.2). Thus, it is imperative that more research be conducted in the area of dialect to continue this growth.

An area of interest to some researchers involves stereotypes and attitudes that are associated with people because of the way they speak. A study of the relationship between personal characteristics and attitudes toward black and white speakers of informal Non-Standard English was conducted to demonstrate the link between cognitive complexity and racial bias, and show how they relate to speakers of informal NonStandard English (Robinson, 1996). Respondents in the study were 135 undergraduate volunteer students (61 females and 74 males) enrolled at the University of Michigan 
taking either a speech fundamental class or a journalism class. The study was a post-test only control group design. The respondents were randomly assigned to 1 of 2 experimental groups. During their regular class period, they listened to a short (45 second) voice recording of an informal non-standard speaking dialect. The speaker's dialectal validity was determined by a class of advanced linguistics students. Four instruments were used in this study: semantic differential scales of 14, 7-point questions, the 2-peer version of Crockett's Role Category Questionnaire to determine the degree of respondents' cognitive complexity, and the Rokeac Race Belief Scale to determine racial prejudice and attitudes. As expected, the results showed that labeling the speaker's racial or ethnic group before presentation of the voice sample tended to elicit more stereotypical answers from the respondents. Respondents indicated that they believed informal NonStandard English speakers were uneducated and were of a low status group. In this study, both speakers were African-American, Ph.D. candidates in sociology. This study's results indicated one significant fact concerning cognitive complexity: it alone is not necessarily a predictor of the respondent's behavioral reaction toward different dialects. They also proved that there is a link between cognitive complexity, racial bias, and language attitudes.

Another research study incorporating the Speech Dialect Attitudinal Scale $(S D A S)$ to examine language attitudes quantified listener attitudes of various dialects (Mulac, 1976). The scale consists of a semantic differential scale with 12 adjective pairs that are alternating in polarity, separated by a 7-point scale. Its purpose was to test the validity of a shortened version of the $S D A S$ to determine if the $S D A S$ can be applied to a broader area of dialectal concepts, and to test if the $S D A S$ can be applied in situations 
where the presentation mode is orthographic, audiotape, or motion picture film. They also examined if male and female ratings differed on the $S D A S$.

Mulac (1976) tested the shortened version of the $S D A S$ across different presentation styles and diverse subjects. The first 2 experiments used transcript as the presentation of the dialect. The next 3 experiments used audiotape as the presentation mode. The experiments using audio tape compared British and American dialects, regional American dialects, and subjects with speech disorders. The subjects in the 6th experiment were individuals with cleft palates and the stimuli were presented by film with sound. The final experiment was a videotaped segment with a broadcast reporter. Six native born, 3 male and 3 female, college educated individuals were selected to be recorded and have their voices used as the audio samples. One male and 1 female from each dialect (Southern California, Eastern Kentucky, and Boston) recorded a 45-second audio clip of a photograph elicited monologue. The 41 subjects were college students and townspeople who were screened and determined to have General American Dialect. Because $\underline{t}$-tests failed to show a significant difference in male versus female responses, the authors combined the responses. In social and intellectual status, the listeners gave their highest rating to Southern California dialect, followed by Boston, then Eastern Kentucky. In aesthetic quality, the highest rating went to Southern California, then Eastern Kentucky, followed by Boston. In the final dimension, dynamism, the highest rating went to Boston, followed by Southern California, then Eastern Kentucky. Thus, listeners stereotyped people who speak with a Southern California dialect as being of high social status, white collar, rich, literate, pleasing, nice, sweet, and beautiful. They 
also stereotyped speakers of a Bostonian dialect as being aggressive, active, strong, and loud.

\section{Hypothesis}

After reviewing existing literature and research studies, it becomes evident that individuals make character judgments and place stereotypes on others due to the way the speaker sounds. However, these stereotypes may not accurately describe characteristics of the different dialect groups.

The primary purpose of this investigation was to determine what stereotypes, if any, are associated with 4 dialects: Appalachian-American, Eastern-American, General American, and African-American. Specifically, (1) are college students who are satisfied with their own dialects more accepting of other individuals? (2) Do college students stereotype others based on dialect? And, (3) does the length of exposure to other dialects allow college students to be more accepting of those dialects?

It is hypothesized that college students who are more accepting of their own dialects will be more accepting of others' characteristics. Further, it is hypothesized that college students are unaware of the fact that they stereotype others based on the way they speak. Finally, it is hypothesized that the longer the length of time a person is exposed to a particular dialect, the more accepting of that dialect he or she becomes.

Selection of the 4 dialects chosen for this investigation was based on several criteria. First, Appalachian-American dialect was selected due to the fact that the study was conducted in an Appalachian region. Also, a large population of students from the 
Northeast region, the Eastern-American dialect was chosen. Standard-American dialect was chosen to provide a comparison to a "standard" versus the other 3 dialect variations. African-American dialect was chosen based on the fact that it remains a topic of controversy today as well as its stigma of being "bad English." 


\section{Chapter 2 - Method}

\section{Participants}

The participants selected for this survey were students enrolled during the fall 2006 semester in SPA 270: Effective Public Speaking, a course at West Virginia University. Because the demographics of this group represented a diverse range of ages and a variety of majors, backgrounds, and hometowns, this particular class was selected as the target population. Although the course enrollment was 250 students, not all were present on the day the survey was distributed. Therefore, 179 surveys were returned and only 143 were used. Data were not calculated from the participants who indicated that American English was not their native language.

\section{Instrument}

The investigator developed the 3 part survey used in this investigation based on a pilot study conducted in the spring of 2005. The pilot study was completed by 75 freshmen enrolled in the West Virginia University Honors College, of which 91\% were from Appalachia. After reviewing additional literature in the field, discussing the investigation with the thesis committee, computing the data and examining the results from the pilot study, revisions were incorporated to enhance the reliability and validity of the current instrument. According to Gay, Mills, \& Airasian (2006), reliability is "the degree to which a test (or qualitative research data) consistently measures whatever it measures." The following definition for validity also was taken from Educational 
Research: Competencies for Analysis and Applications. "Validity is the degree to which a test measures what it is intended to measure; a test is valid for a particular purpose for a particular group. In qualitative research it is the degree to which qualitative data accurately gauges what the researcher is trying to measure" (p. 603).

The survey consisted of 3 sections. Part I was an information section in which respondents completed demographic information. Respondents rated their level of satisfaction with their own speech by using a Likert scale for a series of 9 semantic differential items on Part II. In Part III, respondents completed a semantic differential scale of 10 adjective pairs for a series of different dialect speakers. A semantic differential scale was chosen because by definition it is "an instrument that asks an individual to indicate his or her attitude about a topic by selecting a position on a continuum that ranges from one bipolar adjective to another" (Gay, 2006).

\section{Procedure}

In order to present the subjects with speech samples of male and female speakers of each of the 4 dialects investigated, a group of 32 individuals who appeared to be representative of the 4 dialectal groups being studied were recorded. The sample recordings consisted of the speakers introducing themselves by stating their names, hometowns, and majors at West Virginia University. Then, they were asked to describe the "Cookie Theft" (Appendix B) picture presented in Goodglass, Kaplan, \& Barresi (2001) in 2 to 3 sentences. Also, they read the first paragraph of the "Rainbow Passage" 
(Appendix C) as presented in Fairbanks, (1960). These sample recordings were collected on a hand-held Olympus digital voice recorder (Model no. \# 173665VJP).

Each of these 32 samples was then presented to the thesis committee. The thesis committee, consisting of 5 certified speech-language pathologists, met to review and select the experiment samples. They were presented with 5 African-American male samples; 2 African-American female samples; 2 General-American male samples; 2 General-American female samples; 6 Eastern-American male samples; 5 EasternAmerican female samples; 7 Appalachian-American male samples; and 3 AppalachianAmerican female samples. From these 32 samples, the committee chose 1 female and 1 male to be the most representative of each of the dialects being studied.

After the selection was made by the thesis committee, the 8 individuals were contacted and asked to complete a second recording in the speech lab at West Virginia University. They were recorded in a sound treated booth manufactured by Industrial Acoustics Company, Inc., using a Marantz Supersonic EC-7 Cardioid Condenser microphone and a TEAC Dolby HX Pro double auto reverse cassette deck W-6000R tape recording system. Upon arriving at the speech lab, the college students serving as representative dialect speakers were directed via a script (Appendix A) that was read to them by the investigator. Individually, they were seated in a sound-treated booth and directed to sit with their backs firmly against the back of the chair and their feet flat on the floor. Also, they were directed to hold the microphone 4 inches from their mouths. Each individual was recorded while using 2 to 3 sentences to describe the "Cookie Theft" picture (Goodglass \& Kaplan, 2001) (Appendix B). Then each read the first paragraph of 
the "Rainbow Passage" (Fairbanks, 1960) (Appendix C) and proceeded to explain 2 out of 4 idioms using the following directions:

"Please select 2 or 3 of these idioms to explain to me as if I were from another country. (a.) Read each idiom as it appears on this paper; (b.) Explain each idiom to me as if I were from another country; (c.) Give an example of that idiom in a social or school-related setting."

The idioms are presented in Appendix D.

These specific speech tasks were chosen to assure that all speech samples were similar in content and allowed comparison by the respondents between all 8 speakers. All 3 speech tasks allowed the listener to gain insight into the speaker's morphological and phonological abilities. A photograph elicited monologue was obtained in using the "Cookie Theft" picture in Task 1. Task 2 consisted of reading the given paragraph. Trying to simulate the speaker's "natural dialect" as much as possible, the idioms were used as prompts to maintain common content for Task 3. The speakers' semantic, syntactic, and pragmatic skills as well as their lexicon were used to complete Tasks 1 and 3. Use of these skills allowed the listener to make judgments about the speakers and their linguistic skills.

The tape was converted into .WAV files using Goldwave shareware. Goldwave converted the input signal that was received from the line-in. The settings were set to "FM radio/TV, stereo." The audio was edited using select and delete method. Editing was done to modify the length of the sample and equalize the volume of the samples between all speakers. The WAV files were transferred to a CD to play during the survey via QuickTime Player. Each sample was approximately 90 seconds in length.

A validity check was done to ensure the quality of the 8 speech samples recorded. Ten students from SPA 270; Effective Public Speaking, were selected at random to 
participate in this validity check (Appendix E). They were placed strategically around the test room in each corner and in the center of each side of the room. After listening to the first 20 seconds of each of the 8 speakers, they wrote which dialect they felt each spoke, without having previous information about specific dialects. They were then asked to rate how well they could hear the speaker on the following scale: $1=$ "understood nothing that was said;" 2 = "understood some, but not much of what was said;" 3 = "understood about half of what was said;" 4 = "understood more than half but not all of what was said;" and $5=$ "understood all of what was said." If they circled anything but 5, they were then asked to answer the following question: Please indicate why you could not understand the speaker by circling (A) the acoustic/sound quality of the speaker or (B) the words they spoke and the way they spoke them. Respondents noted that Speaker 1 (mean 3.5; standard deviation 1.0) and Speaker 4 (mean 3.8; standard deviation, 0.90 ) were the most difficult to hear. They were only able to understand about half of what was said by these 2 speakers. In both cases, the respondents indicated that the difficulty came from the words the speaker used and the way he/she spoke, rather than from the acoustic or sound quality of the voice clip. This validity check suggests that the samples were perceptually appropriate to examine the experimental questions.

Before the lecture pertaining to dialect and accent, students enrolled in SPA 270: Effective Public Speaking were asked to complete the 3 part survey. They were presented with a cover letter (Appendix F) stating the purpose of the study as well as that their participation in this survey was completely voluntary, the information would remain 
anonymous and confidential, and that participating in this survey would have no positive or negative effect on their standing at West Virginia University in any manner.

First, respondents were asked to complete Part I (Appendix G), containing demographic and identifying information. This section contained questions regarding their gender, age, major, permanent home city, state, and zip, the city and state in which they were born, and the number of years they have been enrolled at West Virginia University. The students also completed a section listing all the places they had lived during their lifetime and the amount of time they had spent at each of these locations. The remainder of Part I asked questions regarding their race, nationality, and if they were bilingual. If respondents indicated that they were bilingual, they were asked if American English was their first language. They were given the following information regarding dialects:

The United States consists of a variety of dialects. There are many reasons why people speak different dialects and speak English differently: race and ethnicity, region of the country, culture, education, experiences, family and friends. For example, dialect may affect word articulation (i.e., saying 'aks' for 'ask'), pronounciation, (i.e., stressing either the $1^{\text {st }}$ or the $2^{\text {nd }}$ syllable of 'guitar'), or rate of speaking (i.e., rapid vs. slow speech).

Following this definition, the students were asked to answer "yes", "no", or "undecided" regarding whether they speak with a dialect. Those who answered yes were asked to circle 1 of the following options that identified their dialect: African-American, Appalachian, Eastern-American, Standard-American, or Southern. The respondent also had the option of "other" to which they were asked to write out what dialect they felt they spoke.

Part II (Appendix H) consisted of a Likert scale rating 9 questions dealing with their opinions of their own dialects. They were given the following scale to rate their 
answers: 1 = "strongly disagree;" 2 = "I disagree;" 3 = "I don't know" or "I'm undecided;" 4 = "I agree;" and 5 = "I strongly agree." They were asked to rate their responses to the following statements on this scale: I am satisfied with the way I speak; I would like to change the way I speak; I think that the way I speak may prevent me from getting the type of job I want; I think others stereotype me negatively because of the way I speak; I stereotype others negatively because of the way they speak; I think others stereotype me positively because of the way I speak; I stereotype others positively because of the way they speak; I am comfortable speaking to others informally (e.g., socially) because of the way I speak; and The way I speak keeps me from talking to others in formal settings (class speeches, etc.).

After respondents had been given 10 minutes to complete Parts I and II, they were asked to turn to Part III of the survey. They were made aware that they could finish unanswered questions at a later time. Part III consisted of the semantic differential scale rating the 8 speakers on 10 different adjective pairs (Appendix I). The pairs included the following 10 bipolar adjective pairs often used to describe a person's personality characteristics: Unintelligent/Intelligent; Not Approachable/Approachable; Mature/Immature; Motivated/Not Motivated; Powerless/Powerful; Attractive/Not Attractive; Not Friendly/Friendly; Humble/Arrogant; Unstable/Stable; and Eventempered/Argumentative. These particular adjective pairs were chosen because they are common descriptors of a one's personality and character. Also, they were similar to those used in the 1976 study done by Mulac using the SDAS. The 10 adjective pairs were randomized so that half of the negative adjectives appeared on the left side of the answer sheet and the other half of negative adjectives appeared on the right. The respondents 
were asked to listen to the 90 second speech samples of 8 different speakers played using QuickTime player by the instructor. After each clip was played, respondents were given 15 seconds to mark their opinions on the semantic differential scale. The respondents were given the following directions for this section:

On this part, you will find 10 pairs of adjectives that are often used to describe a person's personality with regard to dialect. You will notice that 5 lines appear between the descriptive word pairs. Place an X or a check mark on the line that best describes how you feel about someone who speaks a particular dialect.

You will hear a male and female voice for each of the 4 dialects listed below. Each of the recordings will last for approximately 45 seconds.

An $X$ in the middle of the scale $\left(3^{\text {rd }}\right.$ line) represents a neutral or undecided response. An X at either end of the scale ( $1^{\text {st }}$ or $5^{\text {th }}$ line) means that you are in strong agreement with the adjective closest to that line. An X on the $2^{\text {nd }}$ or $4^{\text {th }}$ line means that your attitude is closely but not extremely closely related to one of the adjectives.

\section{Example}

The example presented below indicates that the person responding to the survey thinks that people who speak like former WVU President David Hardesty are:

Very friendly Approachable

Very mature

Friendly

Not approachable

Immature

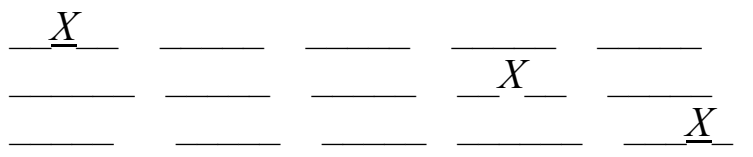

Unfriendly Approachable Mature

The respondents also were prompted to refer to the attachments of the survey consisting of materials that were used during the speech sample recordings: The "Cookie Theft" picture (Appendix B), "the Rainbow Passage" (Appendix C), and Idioms (Appendix D). After the 8th speech sample was played and respondents were given time to mark their answers, they were then prompted to finish any unanswered questions on 
the survey. Once completed, they were asked to submit their surveys and the lecture on dialect and accent proceeded. 


\section{Chapter 3 - Results}

\section{Results of Part I - Identifying Information}

Out of 143 respondents, $107(74.8 \%)$ individuals reported female as their gender and $36(25.2 \%)$ reported male as their gender. 76 of the 143 respondents $(53.1 \%)$ indicated that they were in the 19-20 year old age range. They represented a variety of majors such as: accounting; agronomy; biology; broadcast news; business; chemistry; child development and family studies; criminology; education; English; exercise physiology; forensic science; forestry resource management; general studies; geography; history; industrial engineering; journalism; marketing; mathematics; multiple disciplinary studies; pharmacy; psychology; public relations; recreation and parks management; speech pathology and audiology; sports and exercise psychology; sports management; and wildlife and fisheries. Respondents had attended West Virginia University from one semester to six years; the mean length of time attending WVU was two and a half years.

Respondents reported the following 19 states and Washington, DC, as the states in which they were born: Arizona; California; Connecticut; Florida; Georgia; Illinois; Maryland; Michigan; Missouri; New Jersey; New Mexico; New York; North Carolina; Ohio; Pennsylvania; Texas; Virginia; West Virginia; and Wisconsin. The following 12 states were reported as their home states: Connecticut; Illinois; Maryland; Michigan; Missouri; New Jersey; New York; North Carolina; Ohio; Pennsylvania; Virginia; West Virginia; and Wisconsin. 
With regard to race, $96.5 \%$ were Caucasian, $0.7 \%$ were African American, and $2.8 \%$ reported "other." Those who identified themselves as bilingual or non-native English speakers were excluded from this study, based on the assumption that their lack of experience with the 4 specific dialects might have affected their responses.

The following general information about dialect was presented on the survey. "English spoken in the United States consists of a variety of dialects. There are many reasons why people speak different dialects and speak English differently: race and ethnicity, region of the country, culture, education, experiences, family and friends. Dialect may affect word articulation (i.e., saying 'aks' for 'ask'), pronunciation, (i.e., stressing either the 1st or the 2nd syllable of 'guitar'), or rate of speaking (i.e., rapid vs. slow speech).”

When asked if they spoke a dialect, 46.2\% responded "yes," 36.4\% responded “no," and $17.5 \%$ were "undecided." Of the $46.1 \%$ who responded "yes", the dialect they identified their speech as was General-American (31.8\%), Eastern-American (23.2\%), Appalachian-American (18.9\%), Southern-American (18.9\%), and "other" (7.2\%). These results can be viewed in Figure 1.

\section{Results of Part II - Likert Scale}

The means and standard deviations for each item on Part II, the Likert Scale, are presented in Table 1. The means are ordered from lowest (strongly disagree) to highest (strongly agree) mean. 
On Part II, the majority of respondents reported satisfaction with the way they speak $(95.8 \%)$, were comfortable with the way they speak informally (socially) $(94.4 \%)$ and formally (class presentations) (95.1\%), and they do not feel that others stereotype them negatively based on the way they speak $(87.4 \%)$. They are neutral or undecided if others stereotype them positively based on the way they speak or if ways of speaking played a role in the positive or negative stereotypes of them. Further, respondents did not feel that their dialect may prevent them from getting a job (98.6\%) (Atkins, 1993). Overall, respondents were satisfied with the way they speak (92.3\%).

\section{Results for Part III - Semantic Differential Scale}

After coding and tabulating the semantic differential data, the mean and standard deviation for each adjective pair for each of the 8 speakers in the 4 separate dialects were calculated. In order to determine if there was an overall positive, neutral, or negative stereotype for each dialect, a total mean and standard deviation were calculated for each of the dialects, combining the scores for the male and female representations.

\section{A. Appalachian-American Dialect Results - Part III}

The means and standard deviations for each bipolar adjective pair for the Appalachian-American female speaker are presented in Table 2. According to these results the respondents to this survey "strongly agreed" that she seemed friendly and approachable. Respondents "agreed" that she seemed motivated and humble. They were "undecided/neutral" with regard to whether she seemed even-tempered, stable, attractive, mature, powerful, or intelligent. 
The means and standard deviations for each bipolar adjective pair for the Appalachian-American male speaker are presented in Table 3. According to these results, the respondents to this survey "agreed" that he seemed friendly, humble, approachable, and even-tempered. However, they were "neutral/undecided" regarding the following characteristics: mature, stable, intelligent, attractive, motivated, or powerful.

\section{B. Eastern-American Dialect Results - Part III}

The means and standard deviations for each bipolar adjective pair for the EasternAmerican female speaker are presented in Table 4. According to these results, the respondents to this survey "agreed" that she seemed friendly, approachable, attractive, motivated, and stable. They were "undecided/neutral" regarding whether she seemed intelligent, powerful, mature, even-tempered, or humble.

The means and standard deviations for each bipolar adjective pair for the EasternAmerican male speaker are presented in Table 5. According to these results, the respondents to this survey were "undecided/neutral" regarding whether he seemed eventempered, mature, attractive, stable, humble, intelligent, approachable, powerful, or friendly. Respondents "disagreed" that he seemed motivated.

\section{General-American Dialect Results - Part III}

The means and standard deviations for each bipolar adjective pair for the GeneralAmerican female speaker are presented in Table 6. According to these results, the respondents to this survey "agreed" that she seemed motivated, intelligent, mature, powerful, friendly, stable, approachable, and attractive. Respondents were "undecided/neutral" whether she seemed even-tempered or humble. 
The means and standard deviations for each bipolar adjective pair for the GeneralAmerican male speaker are presented in Table 7. According to these results, the respondents to this survey "agreed" that he seemed intelligent, mature, even-tempered, friendly, stable, approachable, attractive, powerful, and motivated. Respondents were "undecided/neutral" whether he seemed humble.

\section{African-American Dialect Results - Part III}

The means and standard deviations for each bipolar adjective pair for the AfricanAmerican female speaker are presented in Table 8. According to these results the respondents to this survey "strongly agreed" that she seemed friendly and approachable. They "agreed" that she seemed even-tempered, motivated, attractive, stable, mature, humble, and intelligent. Respondents were "undecided/neutral" regarding whether she seemed powerful.

The means and standard deviations for each bipolar adjective pair for the AfricanAmerican male speaker are presented in Table 9. According to these results, the respondents to this survey "agreed" that he seemed friendly and approachable. They were "undecided/neutral" about whether he seemed even-tempered, stable, humble, attractive, or powerful. Respondents "disagreed" that he seemed motivated, mature, and intelligent.

\section{Research Questions: Results}

The primary purpose of this investigation was to determine what stereotypes, if any, are associated with speakers of 4 dialects; Appalachian, Eastern American, Standard 
American, and African-American. (1) Are college students who are satisfied with their own dialect more accepting of other individuals? (2) Do college students stereotype others based on dialect? (3) Does the length of exposure to other dialects allow college students to be more accepting of those dialects?

In order to test Research Question 1 (Are college students who are satisfied with their own dialect more accepting of other individuals?), Pearson Product-Moment correlations were computed. These correlations examined the relationships of respondents' satisfaction with their own dialect (rating on a 5-point Likert scale) with their tolerance of others' dialects (10 semantic differential adjective pairs). Accordingly, 10 correlations were computed. These correlations between personal satisfaction and tolerance were computed using each respondent's average across the 8 speakers. None of these 10 correlations was statistically significant at $p<.05$ alpha level. Although intelligence and motivation correlations with the respondents' personal satisfaction were near significance, all of the correlations were "weak." These correlations are reported in Table 10. Accordingly, the hypothesis was not supported by these research findings.

In order to test Research Question 2, (Do college students stereotype others based on dialect?), a one way; repeated-measures ANALYSIS of VARIANCE (ANOVA) was computed. This is a within-subjects analysis of variance in which repeated-measures across the 8 speakers constituted the comparisons. Thus, dialect was the independent variable (across the 8 speakers). The dependent variable was semantic differential ratings used as a mean across the 10 bipolar adjective pairs. This ANOVA yielded a significant main effect, $F(7,1136)=70.88, p<.001$ alpha level. Accordingly, a highly significant main effect indicated there were differences in the ratings of dialects/speakers by the 
respondents. In order to determine, which speakers were rated higher or lower (differently), a Tukey Test for multiple comparisons was calculated. The results of these multiple comparisons among the 8 speakers can be seen in Table 11 . In that table the 8 means are listed from highest to lowest. The Tukey Test results revealed that each mean in the table was significantly $(p<.01)$ higher than all the means presented below it. Thus, each mean is also significantly $(p<.01)$ lower than all the means presented above it. The results showed the order of ratings to go from highest to lowest for (1) General-American Male, (2) African-American Female, (3) General-American Female, (4) AppalachianAmerican Female, (5) Eastern-American Female, (6) Appalachian-American Male, (7) Eastern-American Male, and (8) African-American Male.

In order to answer Research Question 3, (Does the length of exposure to other dialects allow college students to be more accepting of those dialects?), the respondents needed to be categorized. The number of years in college were as follows: 24 respondents for one year, 54 respondents for two years, 33 respondents for three years, 25 respondents for four years, 4 respondents for five years, and 3 respondents for six years. The categories of years were 1, 2, 3, and 4 in which category 4 included four, five, and six years of attendance.

The correlations were computed between years (values $1,2,3,4)$ with each of the 8 speakers (mean semantic differential ratings). These Pearson Product-Moment correlations are reported in Table 12. As may be noted in Table 12, none of these correlations between years and the speaker dialect variance were found to be significant at $p<.05$ alpha level. Accordingly the hypothesis that the longer the length of time a 
person is exposed to a particular dialect, the more accepting of that dialect he or she becomes, was not supported.

\section{Inter-Dialect Comparison Results}

\section{A. Appalachian-American Dialect Female v. Male Comparison}

When using additional analyses to compare each female and male speaker of the same dialect against each other, some of the general stereotypes of that dialect become more evident. When examining at the Appalachian-American dialect speakers in Figure 2, the Appalachian-American female speaker is rated more positively in 7 out of 10 of the adjective pairs. She is seen as more intelligent, approachable, motivated, powerful, attractive, friendly, and stable. The Appalachian-American male is viewed more positively as mature, humble, and even-tempered. Overall, if the mean of 3.0 is set at neutral, Appalachian-American dialect speakers are viewed positively as approachable, mature, friendly, humble, stable, and even-tempered individuals.

\section{B. Eastern-American Dialect Female v. Male Comparison}

When comparing Eastern-American female speakers to Eastern-American male speakers (Figure 3), it is evident that the Eastern-American female speaker is viewed more positively, since 7 out of 10 means on the adjective pairs are ranked higher. She is viewed as more intelligent, approachable, motivated, powerful, attractive, friendly, and stable than her male counterpart. The Eastern-American male speaker is viewed more mature, humble, and even-tempered than the female speaker. Overall, setting the mean 
of 3.0 as neutral, Eastern-American dialect speakers are viewed as mature, attractive, stable, and even-tempered individuals.

\section{General-American Dialect Female v. Male Comparison}

The comparison of the General-American female speaker to the GeneralAmerican male speaker (Figure 4) indicates a different trend than the other 3 dialects being studied. In this case, the male speaker is rated as being more positively stereotyped in 8 out of 10 of the adjective pairs. He is viewed as more intelligent, approachable, mature, attractive, friendly, humble, stable, and even-tempered than his female counterpart. The General-American female speaker is viewed more positively than the male speaker in being more motivated and powerful. Overall, setting the mean of 3.0 as neutral, General-American dialect speakers are viewed as intelligent, approachable, mature, motivated, powerful, attractive, friendly, stable, even-tempered individuals.

\section{African-American Dialect Female v. Male Comparison}

The final inter-dialect comparison examines the African-American speakers. The African-American female speaker (Figure 5) is viewed more positively in all 10 of the adjective pairs. She is seen as more intelligent, approachable, mature, motivated, powerful, attractive, friendly, humble, stable, and even-tempered than her male counterpart. Overall, setting a mean of 3.0 as neutral, African-American dialect speakers are viewed as approachable, friendly, and even-tempered individuals. 


\section{Gender Comparisons}

\section{A. Female Speaker Comparison}

Another comparison that can be made from all of the data is between the genders. When looking at Figure 6, one can see the comparison of all the female speakers. The General-American female speaker was rated most positively followed by AfricanAmerican, Appalachian-American and Eastern-American. The General-American female speaker was rated more positively in 5 out of 10 adjective pairs. She was seen as more intelligent, mature, motivated, powerful, and stable than her Appalachian-American, Eastern-American, or African-American counterparts. The African-American speaker was viewed more positively in 4 out of 10 of the adjective pairs. She was seen as more approachable, attractive, humble, and even-tempered than her Appalachian-American, Eastern-American, or General-American counterparts. The Appalachian-American dialect speaker was viewed as more positive in only 1 out of 10 adjective pairs. She was seen as more friendly than her Eastern-American, General-American, or AfricanAmerican counterparts. The Eastern-American female speaker was never viewed as the most positive in any of the 10 adjective pairs. Overall, with setting a mean of 3.0 as neutral, female speakers in this study were viewed as approachable, mature, motivated, powerful, attractive, friendly, stable, and even-tempered individuals.

\section{B. Male Speaker Comparison}

When comparing the male speakers of the 4 dialects being studied (Figure 7), the General-American male is rated most positively followed by Appalachian-American, Eastern-American, and African-American. The General-American male speaker was 
viewed more positively in 7 out of 10 of the adjective pairs. He was seen as more intelligent, mature, motivated, powerful, attractive, stable, and even-tempered than his Appalachian-American, Eastern-American, or African-American counterparts. The Appalachian-American male was viewed more positively on 3 out of 10 adjective pairs. He was seen as more approachable, friendly, and humble than his Eastern-American, General-American, or African-American counterparts. The Eastern-American and African-American male speakers were never viewed as the most positive in any of the 10 adjective pairs. Overall, with setting a mean of 3.0 as neutral, the male speakers in this study were viewed as even-tempered.

\section{Overall Dialect Rating Results}

A cumulative mean for each of the 4 dialects was calculated. As was shown in Table 11, respondents assigned the highest mean to the General-American male (3.90); followed by the African-American female (3.86); the General-American female (3.72); the Appalachian-American female (3.55); the Eastern-American female (3.46); the Appalachian-American male (3.35); the Eastern-American male (2.91); and the AfricanAmerican male (2.88).

Overall means for each of the dialects reveal that respondents rated GeneralAmerican dialect speakers most positively with a mean of 3.81 , followed by Appalachian-American dialect speakers (3.45), African-American dialect speakers (3.37), and Eastern-American dialect speakers (3.19). The results from the pilot-test study (completed in 2005) by the investigator demonstrated the following means on the 
semantic differential scale: General-American dialect (3.56); Appalachian-American dialect (3.47); Eastern-American dialect (3.05); and African-American dialect (2.58). This indicates that they assigned negative ratings (negative mean range $=1.00-2.79$ ) overall to African-American English. Additionally, they assigned neutral ratings (neutral mean range $=2.80-3.20)$ to Eastern-American English. Finally, they assigned positive ratings (positive mean range $=3.21-5.00$ ) to both Appalachian-American English and General-American English. These results agree with the current research in which General-American dialect speakers and Appalachian-American dialect speakers are rated more positively than Eastern-American dialect speakers and African-American dialect speakers. 


\section{Chapter 4 - Discussion}

\section{Summary}

The intent of this study was to determine if college students who were more accepting of their own dialects would be more accepting of other dialects. However, the hypothesis was not supported by this investigation. The results of the investigation have indicated that college students are unaware of the fact that they indeed stereotype others due to dialect. In addition, the hypothesis that the longer the length of time a person is exposed to a particular dialect, the more accepting of that dialect he or she becomes also was not supported by the results.

\section{Conclusions}

The findings suggest that individuals do indeed stereotype others, whether positively or negatively, based on the way in which others speak. Generally, the stereotypes identified in this study supported the findings identified in a literature review and also supported Robinson's (1996) research findings in which speakers of NonGeneral-American English were thought to be less educated than speakers of GeneralAmerican English. In addition, study supported Mulac (1976) who found that different stereotypes are associated with different dialects.

On Part I, respondents who completed a 3-part survey included 143 undergraduate students at West Virginia University; 53.1\% were between the ages of 19 and 20 years 
old. The majority (74.8\%) was female and Caucasian (96.5\%). In addition, the majority (46.2\%) felt they spoke with a dialect while $31.8 \%$ identified themselves as speaking with a General-American dialect.

On Part II, respondents indicated personal satisfaction with the way they speak. They also were comfortable speaking in formal and informal settings despite their dialects and did not feel others stereotyped them negatively because of their dialects.

On Part III of this investigation respondents assigned the highest mean to the General-American male (3.90); followed by the African-American female (3.86); the General-American female (3.72); the Appalachian-American female (3.55); the EasternAmerican female (3.46); the Appalachian-American male (3.35); the Eastern-American male (2.91); and the African-American male (2.88). Overall means for each of the dialects reveal that respondents rated General-American dialect speakers most positively with a mean of 3.81, followed by Appalachian-American dialect speakers (3.45), African-American dialect speakers (3.37), and Eastern-American dialect speakers (3.19). Appalachian-American speakers are perceived as approachable, mature, friendly, humble, stable, and even-tempered, with the female being more positively stereotyped than the male. Eastern-American speakers are perceived as mature, attractive, stable, and even-tempered, with the female being more positively stereotyped than the male. General-American speakers are perceived as intelligent, approachable, mature, motivated, powerful, attractive, friendly, stable, and even-tempered, with the male being more positively stereotyped than the female. African-American speakers are perceived as approachable, friendly, and even-tempered, with the female being more positively stereotyped than the male. 
The findings suggest individuals do indeed stereotype others, whether positively or negatively, based on the way in which others speak. For the most part, the stereotypes identified in this study supported the findings identified in a review of the literature. The results of this investigation also supported Robinson's (1996) research findings in which speakers of Non-General-American English were thought to be less educated than speakers of General-American English. This study also was in agreement with Mulac (1976) who found that different stereotypes are associated with different dialects.

Overall, female speakers are perceived as approachable, mature, motivated, powerful, attractive, friendly, stable, and even-tempered, with the General-American dialect being most positively stereotyped. Male speakers are perceived as eventempered, with the General-American dialect being most positively stereotyped.

As depicted in Table 11, respondents assigned the highest mean to the GeneralAmerican male (3.90); followed by the African-American female (3.86); the GeneralAmerican female (3.72); the Appalachian-American female (3.55); the Eastern-American female (3.46); the Appalachian-American male (3.35); the Eastern-American male (2.91); and the African-American male (2.88). Overall means for each of the dialects reveal that respondents rated General-American dialect speakers most positively with a mean of 3.81, followed by Appalachian-American dialect speakers (3.45), African-American dialect speakers (3.37), and Eastern-American dialect speakers (3.19).

Appalachian-American speakers are perceived as approachable, mature, friendly, humble, stable, and even-tempered, with the female being more positively stereotyped than the male. Eastern-American speakers are perceived as mature, attractive, stable, and even-tempered, with the female being more positively stereotyped than the male. 
General-American speakers are perceived as intelligent, approachable, mature, motivated, powerful, attractive, friendly, stable, and even-tempered, with the male being more positively stereotyped than the female. African-American speakers are perceived as approachable, friendly, and even-tempered, with the female being more positively stereotyped than the male. Female speakers are perceived as approachable, mature, motivated, powerful, attractive, friendly, stable, and even-tempered, with the GeneralAmerican dialect being most positively stereotyped. Male speakers are perceived as even-tempered, with the General-American dialect being most positively stereotyped.

\section{Limitations}

It should be noted that results may have been skewed for several reasons. It is possible that the African-American female dialect speaker received extremely positive ratings because she had previous opportunities to develop her oral communication and code-switching skills related to her public debate experience and oral communication courses. In addition, speakers of Appalachian dialects may have received more positive ratings since the survey was conducted in an Appalachian state and $91 \%$ of the respondents reported being from hometowns of the Appalachian region.

Other limitations involve the manner in which the speech samples were recorded. The subjects were instructed to hold the microphone 4 inches from their mouths while speaking. Some subjects may have become nervous during recording and moved the microphone from this position. In retrospect, the use of a microphone stand could have prevented any possible inconsistencies of the speech samples. Also, the group of 
individuals from which the representative speech samples were chosen was small, especially for the African-American speakers. In addition, all of the 8 speech samples presented during the survey were from college educated individuals. The unfamiliar and formal setting of the speech lab and recording booth may have led some of the 8 individuals to code-switch or monitor their dialect and not speak as casually as they would in an informal, social setting. Thus, the 8 recorded speech samples may not have been the most representative of the 4 dialects being studied.

\section{Clinical Implications}

While many are uncomfortable with their dialects, that was not the case with the respondents in this investigation. Those who are uncomfortable, however, may seek the help of a speech-language pathologist who is able to help the individual develop "their desired level of competency in General-American English" as long as they are not replacing their way of speaking or "jeopardizing the integrity of the client's first dialect" (ASHA, 1983, p. 79). Also, in some settings, the SLP may be the expert on dialectal variations and may need to serve as an advocate for the student or patient, i.e. in a classroom where a student is assessed as having insufficient competence in the English language.

It also should be noted that the respondents, who were all undergraduate college students, were unaware that their dialects may prevent them from getting jobs (Atkins, 1993; Atkins \& Kent, 1988). Thus, perhaps higher education institutions should 
emphasize the importance of oral communication and code-switching skills, since respondents stereotyped speakers based only on auditory speech samples.

It is important for individuals to accept each others' differences and realize there are many different ways of speaking in the United States of America today. Further research is warranted in the area of social dialect and language variations. The results of further research in the area of sociolinguistics may bring forth standardized methods for testing culturally and linguistically diverse students and patients. Today, ASHA has taken positions on the issue of dialects and the role of the SLP in assessing, identifying, and treating these individuals. It is imperative to understand that dialectal stereotyping does occur despite the fact that dialects are variations, not disorders.

\section{Suggestions for Future Research}

In the future, repeating this study with participants of different ages, especially children and the elderly might provide a glimpse into when stereotypes are formed and how long they endure. Conducting a similar study using participants whose native language is not American English could also provide interesting results. It could be determined if these stereotypes are world-wide or remain within the boundaries of our nation. 


\section{References}

American Speech-Language-Hearing Association. (2005). Accents and dialects.

Retrieved October 12, 2006, from http://www.asha.org/about/leadershipprojects/multicultural/ad.htm.

American Speech-Language-Hearing Association Committee of the Status of Racial Minorities. (1983) Social Dialect Position Statement. Retrieved October 12, 2006, from http://www.asha.org/NR/rdonlyres/45A7CODC-E9CF-4BO6-B78F = 9F7C2A052F9E/0/19068 1.PDF.

Appalachian Regional Commission. (2005). Counties in Appalachia

Washington, DC [Electronic Version]

http://www.arc.gov/index.do?nodeId=27.

Atkins, C. P. (1993). Do employment recruiters discriminate on the basis of nonstandard dialect? Journal of Employment Counseling, 30, 108-118.

Atkins, C. P. \& Kent, R.L. (1988). What do recruiters consider important during the employment interview? Journal of Employment Counseling, 25, 98-103

Bailey, R.W. (2003). Ideologies, attitudes, and perceptions. American Speech, 88,123-150.

Code switching (2004, September). Speaking Out. Retrieved November 2, 2006, from http://www.usingenglish.com/weblog/archives /000157. html

Fairbanks, G. (1960). The Rainbow Passage. Voice and articulation drill book $\left(2^{\text {nd }} e d.\right)$. New York: Harper \& Brothers. 
Gay, L.R., Mills, G.E., \& Airasian, P. (2006). Educational research: Competencies for analysis and applications $\left(8^{\text {th }}\right.$ ed.). New Jersey: Pearson Prentice Hall.

Goodglass, H., Kaplan, E., \& Barresi, B. (2001). Cookie theft picture. Boston Diagnostic Aphasia Examination ( $3^{\text {rd }}$ ed.). Lippincott, Williams and Wilkins.

Green, L. (2000). Aspectual be-type constructions and coercion in African American English. Natural Language Semantics, 8, 1-25.

Hendrickson, R. (2003). You know you're a New Yorker when you say [Electronic Version] Noo Yawk Tawk: A Dictionary of New York City Expressions. Retrieved from www.nyc24.org/2003/issue3/story5.

Himes, Dr. A. (n.d.) Appalachian studies: History, culture, and folkways. Retrieved October 23, 2004, from http://www.taughtbyhimes.com/appalachia/appalachiaindex.htm,

Identify the English accent you most naturally speak with. (2004) Retrieved October 22, 2004, from http://surveycentral.org/survey/19270.html.

Linguistic geography of Pennsylvania. (2003). Pennsylvania: Evolution Publishing.

McLucas, B. (n.d.). African American Vernacular English: A Brief Overview. Retrieved October 22, 2004, from http://www.arches.uga.edu/-brvan/AAVE/.

McMenamin, G. (2002). Forensic linguistics: Advances in forensic stylistics. New York: CRC Press.

Mulac, A. (1976). Assessment and application of the revised Speech Dialect Attitudinal Scale. Communication Monographs, 43.

Pangilinan, N. (2003). Noo Yawk Tawk [Electronic version]. NYC 24, 3(3), n.p. 
Prometheus Books. (2004) Best Small City in the East. Morgantown Area Chamber of Commerce. Retrieved November 12, 2004, from http://www.mgnchamber.org/ Robinson, J.A. (1996) The relationship between personal characteristics and attitudes toward black and white speakers of informal nonstandard English. The Western Journal of Black Studies, 20.

Sidnell, J. (n.d.) African American Vernacular English (Ebonics). Retrieved April 17, 2007 from http://www.une.edu.au/langnet/definitions/aave.html

Smith, Dr. C. (n.d.) Black Vernacular English: Definitions and debates. [Electronic version]

Tan, A., Fujioka, Y., \& Tan, G. (2000). Television use, stereotypes of African Americans and opinions on affirmative action: An Affective model of policy reasoning. Communications Monographs, 67, 362-371.

Trent, G. (2004) The Language of Appalachia. Retrieved from EzineArticles October 12, 2006, from http://ezinearticles.com/?The-Language-ofAppalachia\&id ${ }^{=} 2393$

U.S. Census Bureau. (2002) Statistical abstract of the United States (Population/Race). Washington, DC: U.S. Government Printing Office. [Electronic Version] http://www.census.gov/statab/www/poprace.html.

Waller, A. (2002). Reviews [Review of Two Worlds in the Tennessee Mountains: Exploring the Origins of Appalachian Stereotypes]. Journal of Social History, 32,4 .

Wolfram,W. (2003). Reexamining the development of African American English: Evidence from isolated communities. Language, 79(2). Retrieved October 10, 
2004 from [Electronic Version].

Wolfram, W., \& Schilling-Estes, N. (1998). American English: Dialects and variation. Massachusetts: Blackwell Publishers. 


\section{Appendix A - Script for Recording}

Good (morning/afternoon)! As you know, my name is Leigh Smitley and I am working on my master's thesis in the speech pathology department. The title of my thesis is College students' perceptions of dialects.

What I need from you to help me complete this study is to record a voice sample. There are 3 separate tasks which will take a total of no more than 5 minutes of your time.

First I ask that you look at the "Cookie theft" picture and give me 3-4 complete sentences of what is going on in this picture.

Second, I ask that you read the "Rainbow Passage" that is provided on this page.

Last, I have 4 idioms written for you on this piece of paper. As defined by Webster's Dictionary, an idiom is an expression whose meaning is not predictable from the usual meanings of the words used. Therefore, it would be difficult for someone who does not speak American English to understand an idiom, like "it's raining cats and dogs." They would initially think cats and dogs were falling from the sky. Please pick 2 or 3 of these idioms and explain them to the listener as if they were from another country. Read the idiom as it appears on this paper, explain it as best as you can in your own words and then give an example of that idiom in a social or school related setting.

I will tell you when to begin speaking. Please speak loud and clear. Do not worry about proper grammar or pronunciation. Speak as you would with a group of friends from home.

If you agree to all of this, we will now proceed with the recording. Again, I would like to state that your participation in this study is completely anonymous, this is completely on a voluntary basis, it will not affect your standing at WVU in any way, and that being a participant will not cause you any harm in any manner.

Thank you for your participation in this study. It is greatly appreciated. Have a nice day. 
Appendix B- "Cookie Theft" Picture

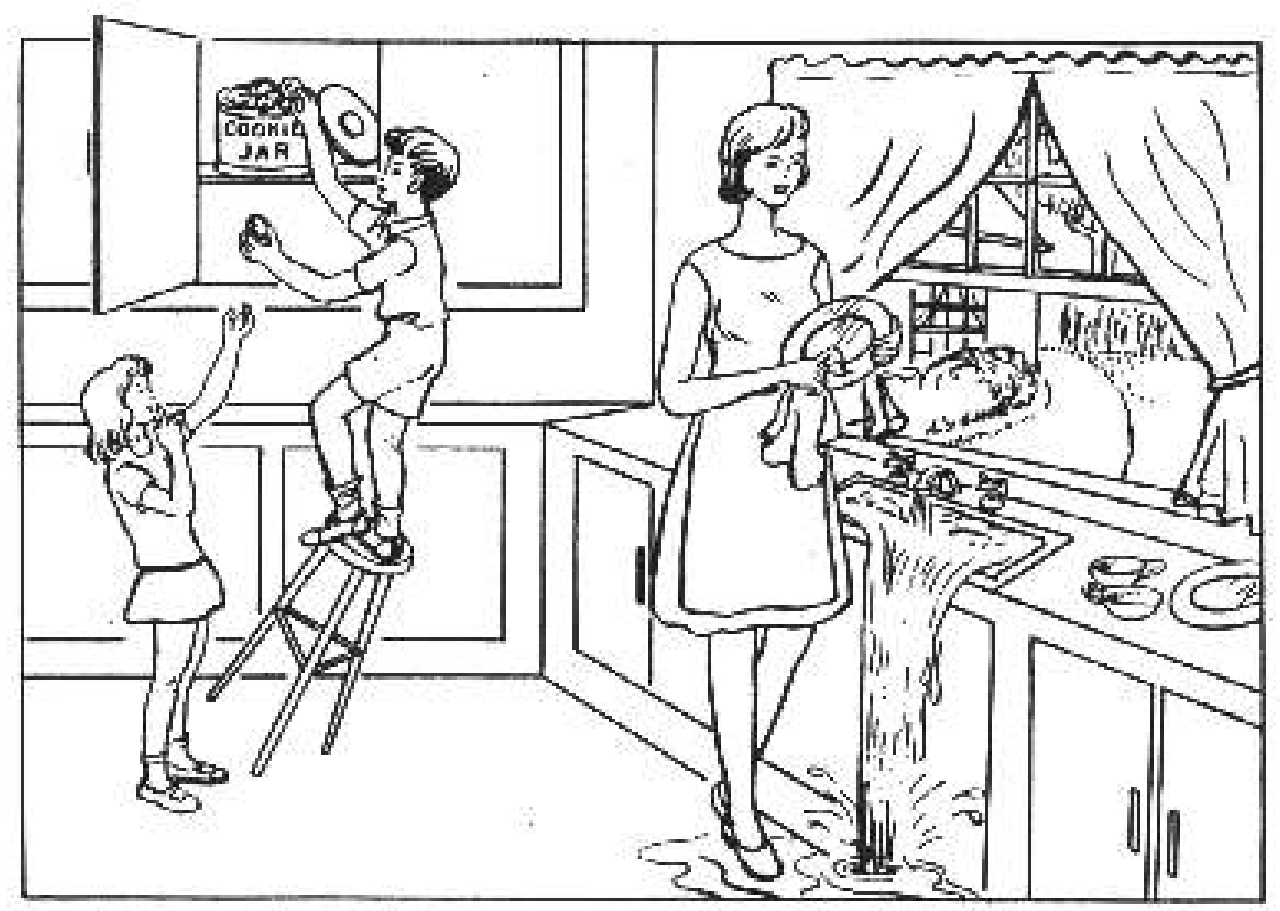




\section{Appendix C - The "Rainbow Passage" Paragraph}

When sunlight strikes raindrops in the air, they act like a prism and form a rainbow. The rainbow is a division of white light into many beautiful colors. These take the shape of a long round arch, with its path high above, and its two ends apparently beyond the horizon. There is, according to legend, a boiling pot of gold at one end. People look, but no one ever finds it. When a man looks for something beyond his reach, his friends say he is looking for the pot of gold at the end of the rainbow. 


\section{Appendix D - Idioms}

\section{Directions:}

Please select 2 or 3 of these idioms to explain to me as if I were from another country.
a. Read each idiom as it appears on this paper.
b. Explain each idiom to me as if I were from another country.
c. Give an example of that idiom in a social or school-related setting.

1. The grass is greener on the other side.

2. Have your cake and eat it too.

3. Eat your words.

4. When the cat's away, the mice will play. 


\section{Appendix E - Validity Check Test Form}

\section{Listen to the following 8 voice clips and follow the directions provided.}

1.) Write the type of dialect you feel each speaker has on the line corresponding to that speaker.

2.) Circle which gender you feel matches each speaker

3.) Indicate how well you could hear the speaker by circling:

1. understood nothing that was said

2. understood some, but not much of what was said

3. understood about half of what was said

4. understood more than half but not all of what was said

5. understood all of what was said

If you circle anything but a 5, please indicate why you could not understand the speaker by circling:

A. the acoustic/sound quality of the speaker

B. the words they spoke and the way they spoke them

Label Dialect Gender Could you understand the speaker?

Speaker 1

$\mathrm{M} \mathrm{F}$

$\begin{array}{lllll}1 & 2 & 3 & 4 & 5\end{array}$

A B

Speaker 2

$\mathrm{M} F$

$\begin{array}{lllll}1 & 2 & 3 & 4 & 5\end{array}$

A B

Speaker 3

M F

$\begin{array}{lllll}1 & 2 & 3 & 4 & 5\end{array}$

A B

Speaker 4

M F

$\begin{array}{lllll}1 & 2 & 3 & 4 & 5\end{array}$

A B

Speaker 5

M F

$\begin{array}{lllll}1 & 2 & 3 & 4 & 5\end{array}$

A B

Speaker 6

M F

$\begin{array}{lllll}1 & 2 & 3 & 4 & 5\end{array}$

A B

Speaker 7

M F

$\begin{array}{lllll}1 & 2 & 3 & 4 & 5\end{array}$

A B

Speaker 8

M F

$\begin{array}{lllll}1 & 2 & 3 & 4 & 5\end{array}$

A B 


\section{Appendix F - Cover Letter for Instrument}

\section{West Virginia University \\ College of Human Fesources and Education}

October 31,2006

Dear Participant,

My name is Leigh Smitley and I am a fourth semester graduate student in speechlanguage pathology at West Virginia University. Currently, I am working on my master's thesis. My committee consists of Dr. Carolyn P. Atkins (Chair of Thesis Committee), Dr. Lynn R. Cartwright, Dr, Cheryl R. Prichard, Dr. Dennis M. Ruscello, and Dr. Mary Ellen Tekieli Koay.

I am requesting your participation in this research project entitled College Students' Perceptions of Dialects. The parpose of this study is to collect information regarding how college students perceive different dialects.

This survey is strictly on a wolunteer basis: you are not required to participate. If you choose not to participate in part or all of this survey, your grade or standing at West Virginia University or on any athletic team or in any organization will not be affected.

Please do not put your name on this survey. All the tesponses to this survey will remain anonymous and confidential; no respondents will be identified. Although you do not have to answer every question, research data will be strengthened if you do.

Thank you for your participation.

Sincerely,

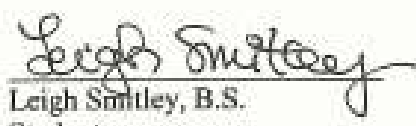

Student

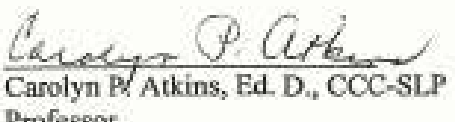

Professor

Department of Speech Patholegy and Audiology 


\section{Appendix G - Part I of Instrument}

Part 1. Identifying Information

Gender: Male Female Age Range: 17-18 19-20 21+

Major: Years at WVU(including current year):

Permanent Home Address:

City State Country

Place you were born:

City State Country

List all the places you have ever lived and length of time spent there in years:

(if less than 1 year, put $<1$; you may also use $1 / 2$ years as well, ie., $4 \frac{1}{2}$ years; if you have lived in the listed address all your life, put always)

\begin{tabular}{llll}
\hline City & State & Country & Years Lived \\
\hline City & State & Country & Years Lived \\
\hline City & State & Country & Years Lived \\
\hline City & State & Country & Years Lived \\
\hline City & & & State \\
\end{tabular}

Race: Caucasian African-American Other:

Nationality:

Are you bilingual? Y N

Is American English your first language: $\mathrm{Y} \quad \mathrm{N}$

If No, what is your first language? 


\section{Dialect Definition:}

The United Staes Consists of a variety of dialects. There are many reasons why people speak different dialects and speak English differently: race and ethnicity, region of the country, culture, education, experiences, family and friends. For example, dialect may affect word articulation (i.e., saying 'aks' for 'ask'), pronounciation, (i.e., stresssing either the $1^{\text {st }}$ or the $2^{\text {nd }}$ syllable of 'guitar'), or rate of speaking (i.e., rapid vs. slow speech).

I speak with a dialect: $\quad$ Yes $\quad$ No Undecided

If yes, I speak with ___ dialect. ( circle one below or complete the blank)

African-American Dialect Appalachian Dialect Eastern American Dialect

Standard American Dialect Southern Dialect Other (be specific): 


\section{Appendix H - Part II of Instrument}

\section{Part II. Likert Scale}

Directions: Using the following key, please circle your answer from 1 to 5 on the items.

Key

$$
\begin{aligned}
& 1=\text { I strongly disagree } \\
& 2=\text { I disagree } \\
& 3=I \text { don't know or I'm undecided } \\
& 4=\text { I agree } \\
& 5=\text { I strongly agree }
\end{aligned}
$$

1. I am satisfied with the way I speak.

$\begin{array}{lllll}1 & 2 & 3 & 4 & 5\end{array}$

2. I would like to change the way I speak.

$\begin{array}{lllll}1 & 2 & 3 & 4 & 5\end{array}$

3. I think that the way I speak may prevent me from getting the type of job that I want.

$\begin{array}{lllll}1 & 2 & 3 & 4 & 5\end{array}$

4. I think others stereotype me negatively because of the way I speak .

$\begin{array}{lllll}1 & 2 & 3 & 4 & 5\end{array}$

5. I stereotype others negatively because of the way they speak.

$\begin{array}{lllll}1 & 2 & 3 & 4 & 5\end{array}$

6. I think that others stereotype me positively because of they way I speak.

$\begin{array}{lllll}1 & 2 & 3 & 4 & 5\end{array}$

7. I stereotype others positively because of the way they speak.

8. I am comfortable speaking to others informally (e.g., socially) because of the way I speak.

$\begin{array}{lllll}1 & 2 & 3 & 4 & 5\end{array}$

9. The way I speak keeps me from talking others in formal settings (class speeches).

$\begin{array}{lllll}1 & 2 & 3 & 4 & 5\end{array}$




\section{Appendix I - Part III of Instrument}

\section{Part III. Semantic Differential Scale}

On this part, you will find 10 pairs of adjectives that are often used to describe a person's personality with regard to dialect. You will notice that 5 lines appear between the descriptive word pairs. Place an X or a check mark on the line that best describes how you feel about someone who speaks a particular dialect.

You will hear a male and female voice for each of the 4 dialects listed below. Each of the recordings will last for approximately 45 seconds. See attachments at the end of this survey to following along with speech sample.

An $X$ in the middle of the scale $\left(3^{\text {rd }}\right.$ line) represents a neutral or undecided response. An $\mathrm{X}$ at either end of the scale $\left(1^{\text {st }}\right.$ or $5^{\text {th }}$ line) means that you are in strong agreement with the adjective closest to that line. An X on the $2^{\text {nd }}$ or $4^{\text {th }}$ line means that your attitude is closely but not extremely closely related to one o the adjectives.

\section{Example}

The example presented below indicates that the person responding to the survey thinks that people who speak like former WVU President David Hardesty are:

Very friendly

Approachable

Very mature

Friendly

Not approachable

Immature

Speaker 1

Unintelligent

Not Approachable

Mature

Motivated

Powerless

Attractive

Not Friendly

Humble

Unstable

Even-tempered

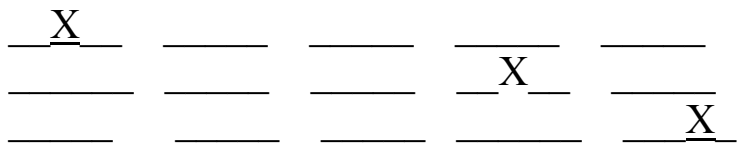

Unfriendly

Approachable

Mature
Intelligent

Approachable

Immature

Not Motivated

Powerful

Not Attractive

Friendly

Arrogant

Stable

Argumentative 
Speaker 2

Unintelligent

Not Approachable

Mature

Motivated

Powerless

Attractive

Not Friendly

Humble

Unstable

Even-tempered

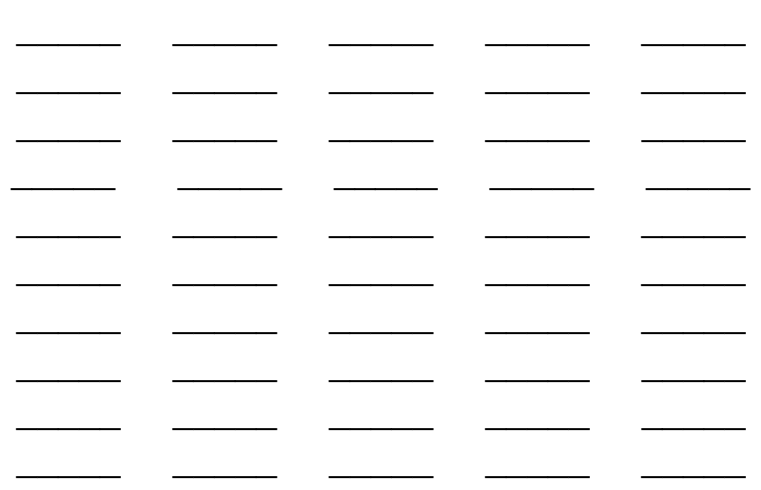

Intelligent

Approachable Immature

Not Motivated

Powerful

Not Attractive

Friendly

Arrogant

Stable

Argumentative

Speaker 3

Unintelligent

Not Approachable

Mature

Motivated

Powerless

Attractive

Not Friendly

Humble

Unstable

Even-tempered

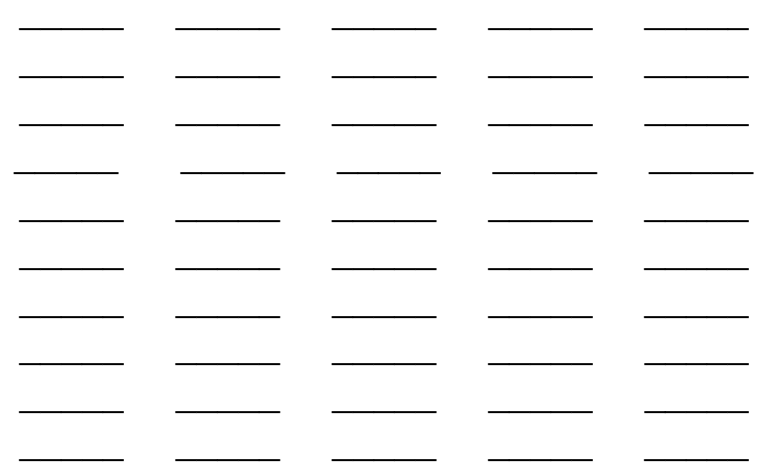

Intelligent

Approachable Immature

Not Motivated

Powerful

Not Attractive

Friendly

Arrogant

Stable

Argumentative

Speaker 4

Unintelligent

Not Approachable

Mature

Motivated

Powerless

Attractive

Not Friendly

Humble

Unstable

Even-tempered

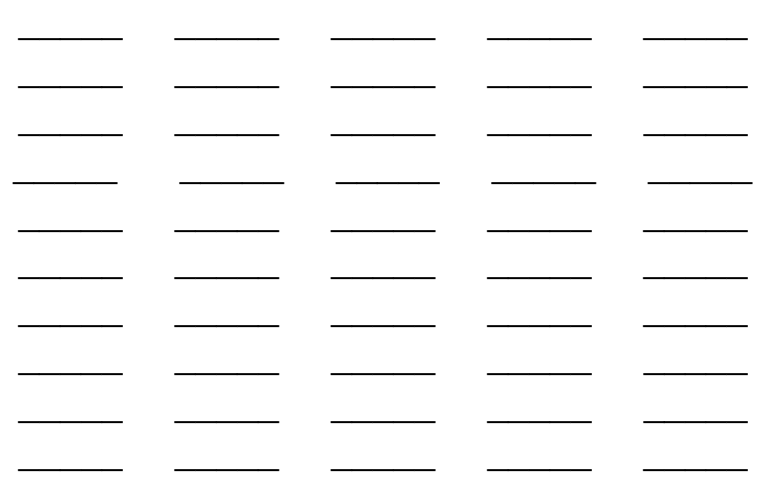

Intelligent

Approachable Immature

Not Motivated

Powerful

Not Attractive

Friendly

Arrogant

Stable

Argumentative 
Speaker 5

Unintelligent

Not Approachable

Mature

Motivated

Powerless

Attractive

Not Friendly

Humble

Unstable

Even-tempered

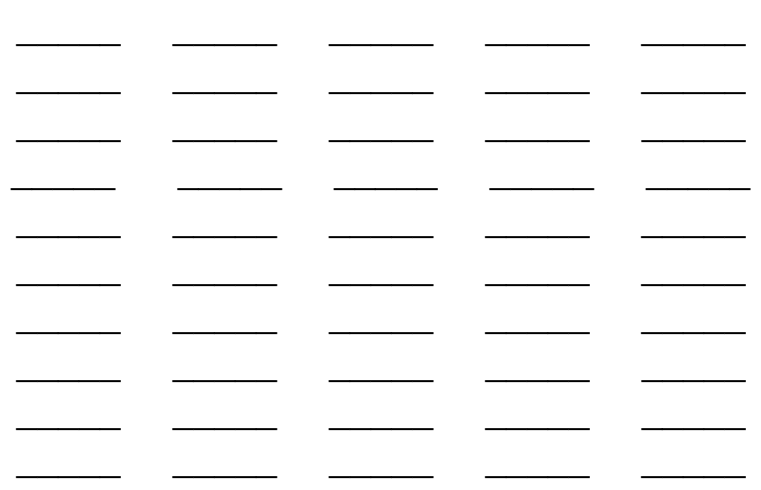

Intelligent

Approachable Immature

Not Motivated

Powerful

Not Attractive

Friendly

Arrogant

Stable

Argumentative

Speaker 6

Unintelligent

Not Approachable

Mature

Motivated

Powerless

Attractive

Not Friendly

Humble

Unstable

Even-tempered

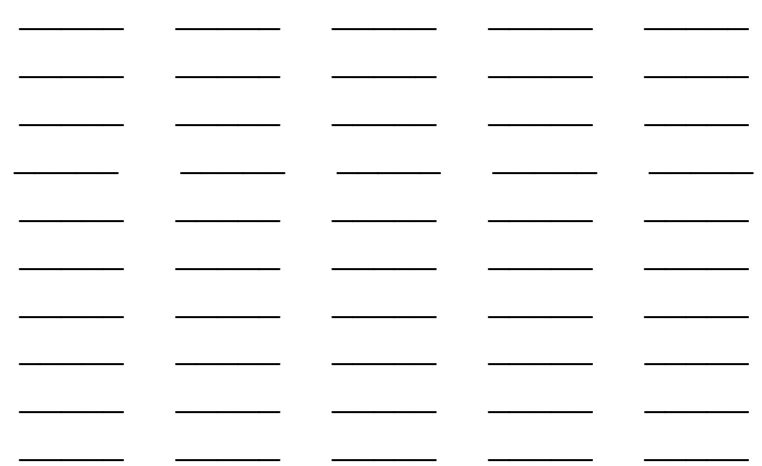

Intelligent

Approachable Immature

Not Motivated

Powerful

Not Attractive

Friendly

Arrogant

Stable

Argumentative

Speaker 7

Unintelligent

Not Approachable

Mature

Motivated

Powerless

Attractive

Not Friendly

Humble

Unstable

Even-tempered

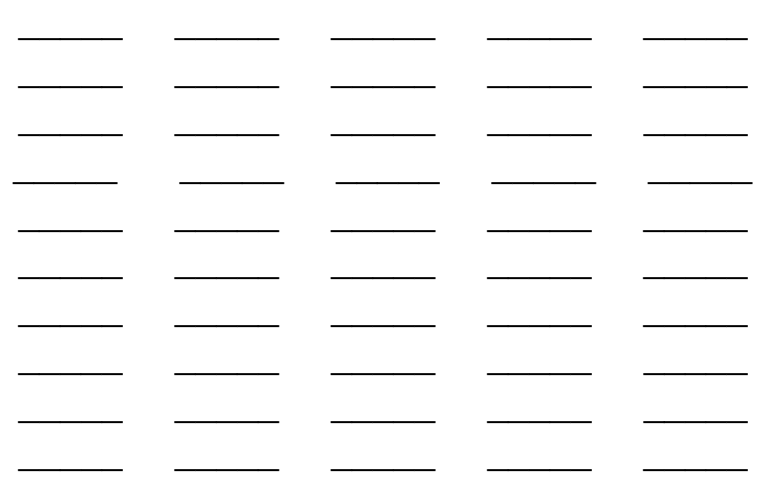

Intelligent

Approachable Immature

Not Motivated

Powerful

Not Attractive

Friendly

Arrogant

Stable

Argumentative 
Speaker 8

Unintelligent

Not Approachable

Mature

Motivated

Powerless

Attractive

Not Friendly

Humble

Unstable

Even-tempered

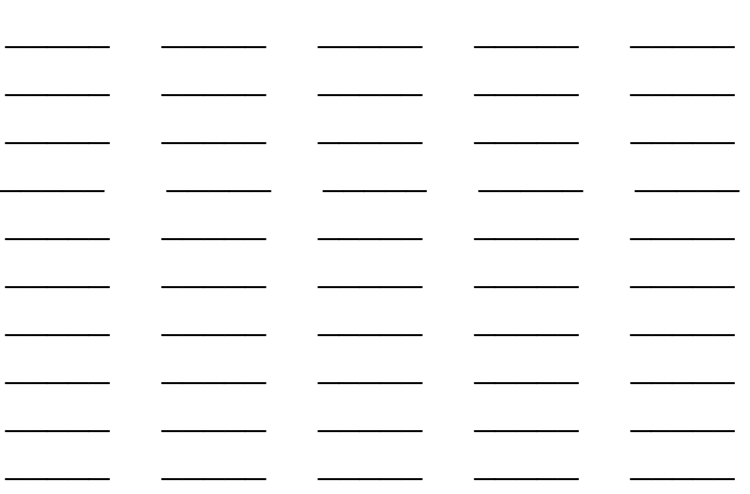

Intelligent

Approachable Immature

Not Motivated

Powerful

Not Attractive

Friendly

Arrogant

Stable

Argumentative 
Table 1

Means and Standard Deviations Regarding College Students'Attitudes on Their Own Dialects

Item Mean SD

I think that the way I speak may prevent $\quad 1.50 \quad 0.80$

me from getting the type of job I want.

The way I speak keeps me from talking to

1.69

0.94

others in formal settings (class speeches).

I think others stereotype me negatively

1.74

0.99

because of the way I speak.

I would like to change the way I speak.

1.79

0.93

I stereotype others negatively

2.28

1.11

because of the way they speak.

I think that others stereotype me

3.15

1.04

positively because of the way I speak. 
I stereotype others positively because

of the way they speak.

I am comfortable speaking to others informally

(e.g., socially) because of the way I speak.

I am satisfied with the way I speak.

*Key: 1=I strongly disagree, 2=I disagree, $3=\mathrm{I}$ don't know or I'm undecided, 4=I agree, 5=I strongly agree
$3.33 \quad 1.02$

$4.24 \quad 0.89$

$4.35 \quad 0.75$ 
Table 2

Means and Standard Deviations for the 10 Bipolar Adjective Pairs for AppalachianAmerican Female Speaker

\begin{tabular}{llc} 
Item & $\alpha$ Mean & $\mathrm{SD}$ \\
\hline Unintelligent/ Intelligent & 2.97 & 1.07 \\
Powerless/Powerful & 3.11 & 0.98 \\
Immature/Mature & 3.18 & 1.02 \\
Not Attractive/Attractive & 3.29 & 0.98 \\
Unstable/Stable & 3.34 & 1.01 \\
Argumentative/Even-tempered & 3.39 & 1.28 \\
Arrogant/Humble & 3.69 & 1.10 \\
Not Motivated/Motivated & 3.83 & 0.88 \\
Not Approachable/Approachable & 4.27 & 0.83 \\
Not Friendly/Friendly & 4.43 & 0.87 \\
& & \\
\hline
\end{tabular}

Note: Negative adjectives appear on the left; Positive adjectives appear on the right.

$\alpha=$ The table reads with most negatively (lowest mean) perceived adjective on top and most positively (highest mean) perceived adjective on the bottom. The lower means indicate ratings toward the more negative side of the scale. For example a mean of 2.97 for "unintelligent/intelligent" indicates that the respondent judged female Appalachian-American dialect speakers to be neutral on this issue. 
Table 3

Means and Standard Deviations for the 10 Bipolar Adjective Pairs for AppalachianAmerican Male Speaker

Item

$\alpha$ Mean

SD

Powerless/Powerful

Not Motivated/Motivated

Not Attractive/Attractive

Unintelligent/ Intelligent

Unstable/Stable

Immature/Mature

Argumentative/Even-tempered

Not Approachable/Approachable

Arrogant/Humble

Not Friendly/Friendly
2.65

0.87

2.72

0.95

2.80

0.98

2.80

0.84

3.20

0.98

3.20

0.85

3.92

0.94

4.03

0.83

4.09

0.87

4.13

0.96

Note: Negative adjectives appear on the left; Positive adjectives appear on the right.

$\alpha=$ The table reads with most negatively (lowest mean) perceived adjective on top and most positively (highest mean) perceived adjective on the bottom. The lower means indicate ratings toward the more negative side of the scale. For example a mean of 2.65 for "powerless/powerful" indicates that the respondent judged male Appalachian-American dialect speakers to be neutral on this issue. 
Table 4

Means and Standard Deviations for the 10 Bipolar Adjective Pairs for Eastern-American Female Speaker

\begin{tabular}{lcc} 
Item & $\alpha$ Mean & \\
\hline & & 1.05 \\
Arrogant/Humble & 2.94 & 1.16 \\
Argumentative/Even-tempered & 3.13 & 1.16 \\
Immature/Mature & 3.15 & 0.94 \\
Powerless/Powerful & 3.22 & 0.98 \\
Unintelligent/ Intelligent & 3.36 & 0.93 \\
Unstable/Stable & 3.43 & 0.92 \\
Not Motivated/Motivated & 3.66 & 0.89 \\
Not Attractive/Attractive & 3.71 & 0.98 \\
Not Approachable/Approachable & 3.93 & 1.05 \\
Not Friendly/Friendly & 4.08 & \\
& & \\
& &
\end{tabular}

Note: Negative adjectives appear on the left; Positive adjectives appear on the right.

$\alpha=$ The table reads with most negatively (lowest mean) perceived adjective on top and most positively (highest mean) perceived adjective on the bottom. The lower means indicate ratings toward the more negative side of the scale. For example a mean of 2.94 for "arrogant/humble" indicates that the respondent judged female Eastern-American dialect speakers to be neutral on this issue. 
Table 5

Means and Standard Deviations for the 10 Bipolar Adjective Pairs for Eastern-American Male Speaker

Item

$\alpha$ Mean

SD

Not Motivated/Motivated

Not Friendly/Friendly

2.75

1.03

Powerless/Powerful

2.76

1.05

Not Approachable/Approachable

2.77

1.08

Unintelligent/ Intelligent

2.78

0.93

Arrogant/Humble

3.02

1.01

Unstable/Stable

3.10

0.88

Not Attractive/Attractive

3.15

0.93

Immature/Mature

3.22

0.98

Argumentative/Even-tempered

3.29

1.09

Note: Negative adjectives appear on the left; Positive adjectives appear on the right.

$\alpha=$ The table reads with most negatively (lowest mean) perceived adjective on top and most positively (highest mean) perceived adjective on the bottom. The lower means indicate ratings toward the more negative side of the scale. For example a mean of 2.29 for "not motivated/motivated" indicates that the respondent judged male Eastern-American dialect speakers to be "not motivated." 
Table 6

Means and Standard Deviations for the 10 Bipolar Adjective Pairs for GeneralAmerican Female Speaker

Item

$\alpha$ Mean

SD

Arrogant/Humble

Argumentative/Even-tempered

Not Attractive/Attractive

Not Approachable/Approachable

Unstable/Stable

Not Friendly/Friendly

Powerless/Powerful

Immature/Mature

Unintelligent/ Intelligent

Not Motivated/Motivated
2.98

3.14

3.48

3.80

3.81

3.81

3.87

3.96

4.13

4.19
1.21

1.27

1.03

1.03

1.07

1.09

0.88

0.97

0.87

0.80

Note: Negative adjectives appear on the left; Positive adjectives appear on the right.

$\alpha=$ The table reads with most negatively (lowest mean) perceived adjective on top and most positively (highest mean) perceived adjective on the bottom. The lower means indicate ratings toward the more negative side of the scale. For example a mean of 2.98 for "arrogant/humble" indicates that the respondent judged female General-American dialect speakers to be "humble." 
Table 7

Means and Standard Deviations for the 10 Bipolar Adjective Pairs for GeneralAmerican Male Speaker

\begin{tabular}{lcc} 
Item & $\alpha$ Mean & \\
\hline & & \\
Arrogant/Humble & 3.52 & 0.97 \\
Not Motivated/Motivated & 3.58 & 1.04 \\
Powerless/Powerful & 3.69 & 0.86 \\
Not Attractive/Attractive & 3.77 & 0.84 \\
Not Approachable/Approachable & 3.97 & 0.92 \\
Unstable/Stable & 3.98 & 0.85 \\
Not Friendly/Friendly & 4.01 & 0.81 \\
Argumentative/Even-tempered & 4.10 & 0.83 \\
Immature/Mature & 4.15 & 1.09 \\
Unintelligent/ Intelligent & 4.18 & 0.85 \\
& & \\
\hline
\end{tabular}

Note: Negative adjectives appear on the left; Positive adjectives appear on the right.

$\alpha=$ The table reads with most negatively (lowest mean) perceived adjective on top and most positively (highest mean) perceived adjective on the bottom. The lower means indicate ratings toward the more negative side of the scale. For example a mean of 3.52 for "arrogant/humble" indicates that the respondent judged male General-American dialect speakers to be neutral on this issue. 
Table 8

Means and Standard Deviations for the 10 Bipolar Adjective Pairs for African-American Female Speaker

\begin{tabular}{lcc} 
Item & $\alpha$ Mean & SD \\
\hline Powerless/Powerful & 3.31 & 0.82 \\
Unintelligent/ Intelligent & 3.66 & 0.80 \\
Arrogant/Humble & 3.71 & 0.95 \\
Immature/Mature & 3.76 & 0.95 \\
Unstable/Stable & 3.78 & 0.79 \\
Not Attractive/Attractive & 3.83 & 0.82 \\
Not Motivated/Motivated & 3.92 & 0.81 \\
Argumentative/Even-tempered & 3.94 & 0.88 \\
Not Approachable/Approachable & 4.31 & 0.73 \\
Not Friendly/Friendly & 4.35 & 0.73 \\
& & \\
\hline
\end{tabular}

Note: Negative adjectives appear on the left; Positive adjectives appear on the right.

$\alpha=$ The table reads with most negatively (lowest mean) perceived adjective on top and most positively (highest mean) perceived adjective on the bottom. The lower means indicate ratings toward the more negative side of the scale. For example a mean of 3.31 for "powerless/powerful" indicates that the respondent judged female African-American dialect speakers to be neutral on this issue. 
Table 9

Means and Standard Deviations for the 10 Bipolar Adjective Pairs for African-American Male Speaker

Item

$\alpha$ Mean

SD

Unintelligent/ Intelligent

Immature/Mature

Not Motivated/Motivated

Powerless/Powerful

Not Attractive/Attractive

Arrogant/Humble

Unstable/Stable

Argumentative/Even-tempered

Not Approachable/Approachable

Not Friendly/Friendly
2.19

2.33

2.38

2.69

2.80

2.82

2.98

3.20

3.51

3.87
0.84

0.87

0.94

1.07

0.87

1.21

1.01

1.15

1.13

0.96

Note: Negative adjectives appear on the left; Positive adjectives appear on the right.

$\alpha=$ The table reads with most negatively (lowest mean) perceived adjective on top and most positively (highest mean) perceived adjective on the bottom. The lower means indicate ratings toward the more negative side of the scale. For example a mean of 2.19 for "unintelligent/intelligent" indicates that the respondent judged male African-American dialect speakers to be "unintelligent". 
Table 10

Correlations between the Respondents' Personal Satisfaction of Own Dialect with Tolerance of Others' Characteristics

Variable

Intelligence

Approachability

Maturity

Motivation

Power

Attractiveness

Friendliness

Arrogance

Stability

Argumentativeness
Correlation

$p<.05$ no

no

no

no

no

no

no

no

no

no 
Table 11

Overall Mean Dialect Comparisons

Dialects Compared Dialect (mean)

General-American Male

African-American Female

General-American Female

Appalachian-American Female

Eastern-American Female

Appalachian-American Male

Eastern-American Male

African-American Male
3.90

3.86

3.72

3.55

3.46

3.35

2.91

2.88

Note: Each mean in the table is significantly $(p<.01)$ higher than all the means presented below it. Thus, each mean is also significantly $(p<.01)$ lower than all the means presented above it. 
Table 12

Correlations between the Years Spent at West Virginia University and the Acceptance of Each Speaker

\begin{tabular}{lll} 
Dialect & Correlation & $p<.05$ \\
\hline AppAmM & 0.036 & no \\
EaAmF & -0.052 & no \\
GenAmM & -0.034 & no \\
AfAmM & 0.027 & no \\
GenAmF & -0.088 & no \\
AppAmF & -0.067 & no \\
EaAmM & -0.099 & no \\
AfAmF & -0.049 & no \\
\hline
\end{tabular}

Note: The years of attendance at West Virginia University were categorized into values 1, 2, 3, and 4, in which 4 included four, five, and six years of attendance. 
Figure 1. Self-Reported Dialects of Respondents $(n=66)$

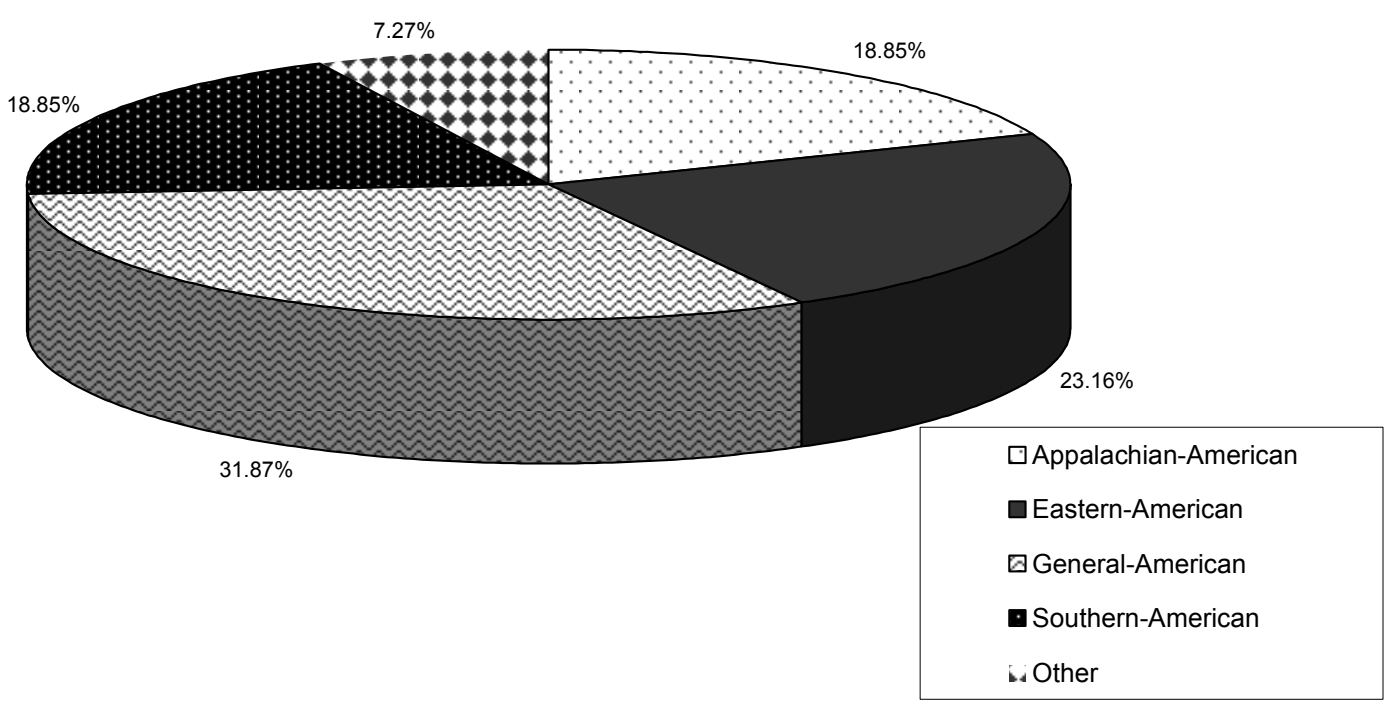


Figure 2 - Semantic Differential Means: Appalachian-American Female v. Male $(n=143)$

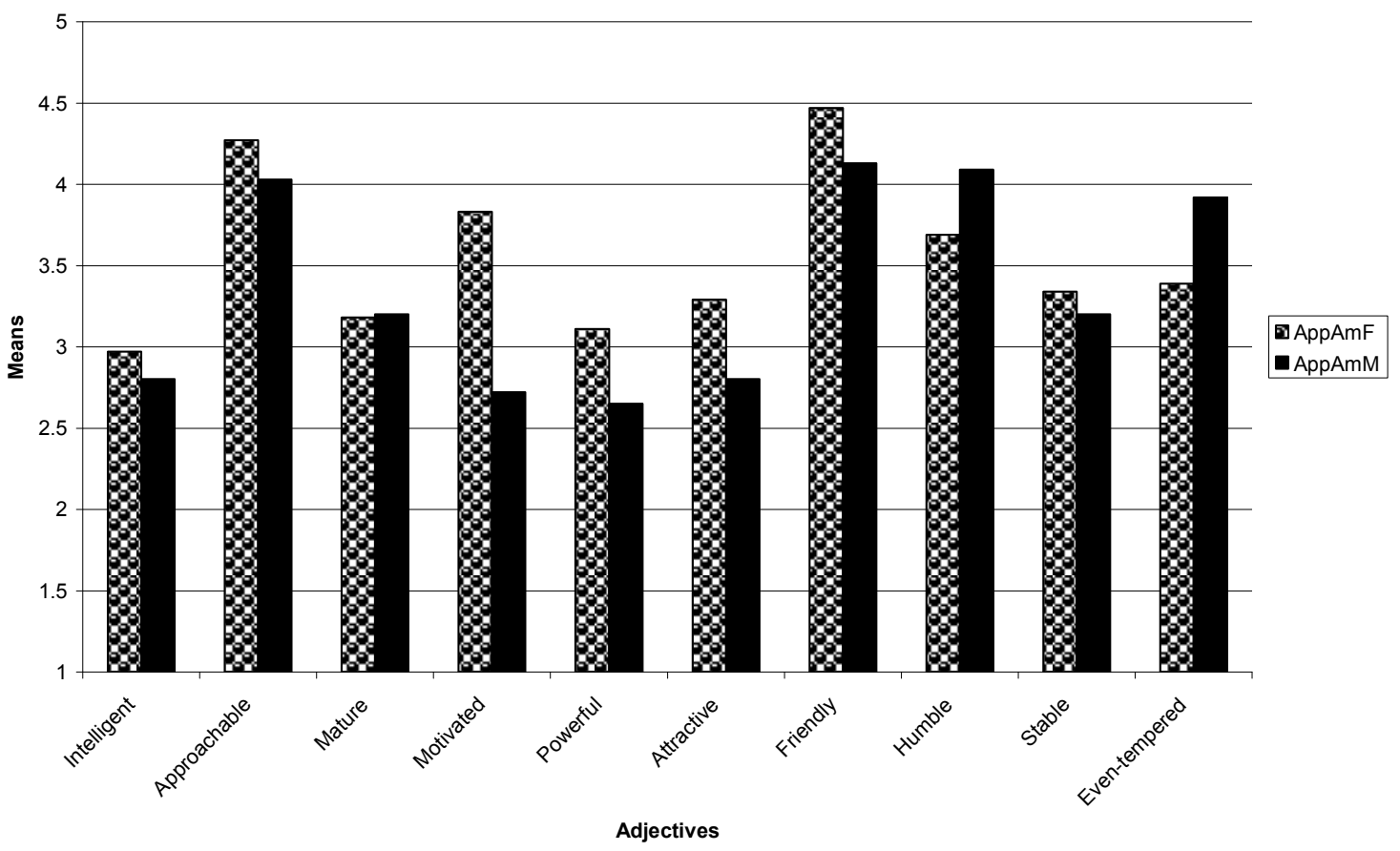


Figure 3 - Semantic Differential Means: Eastern-American Female v. Male $(n=143)$

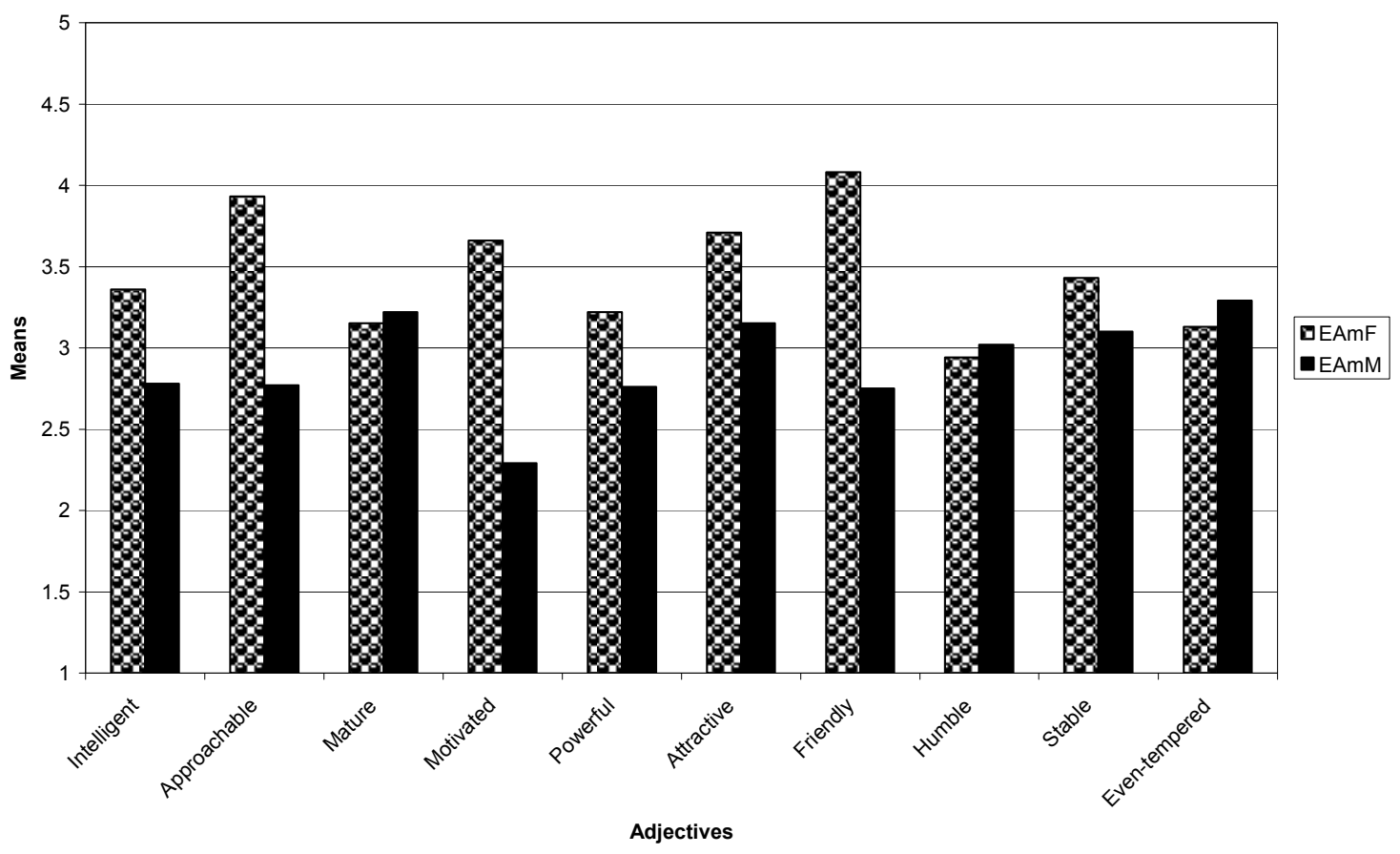


Figure 4 - Semantic Differential Means: General-American Female v. Male $(n=143)$

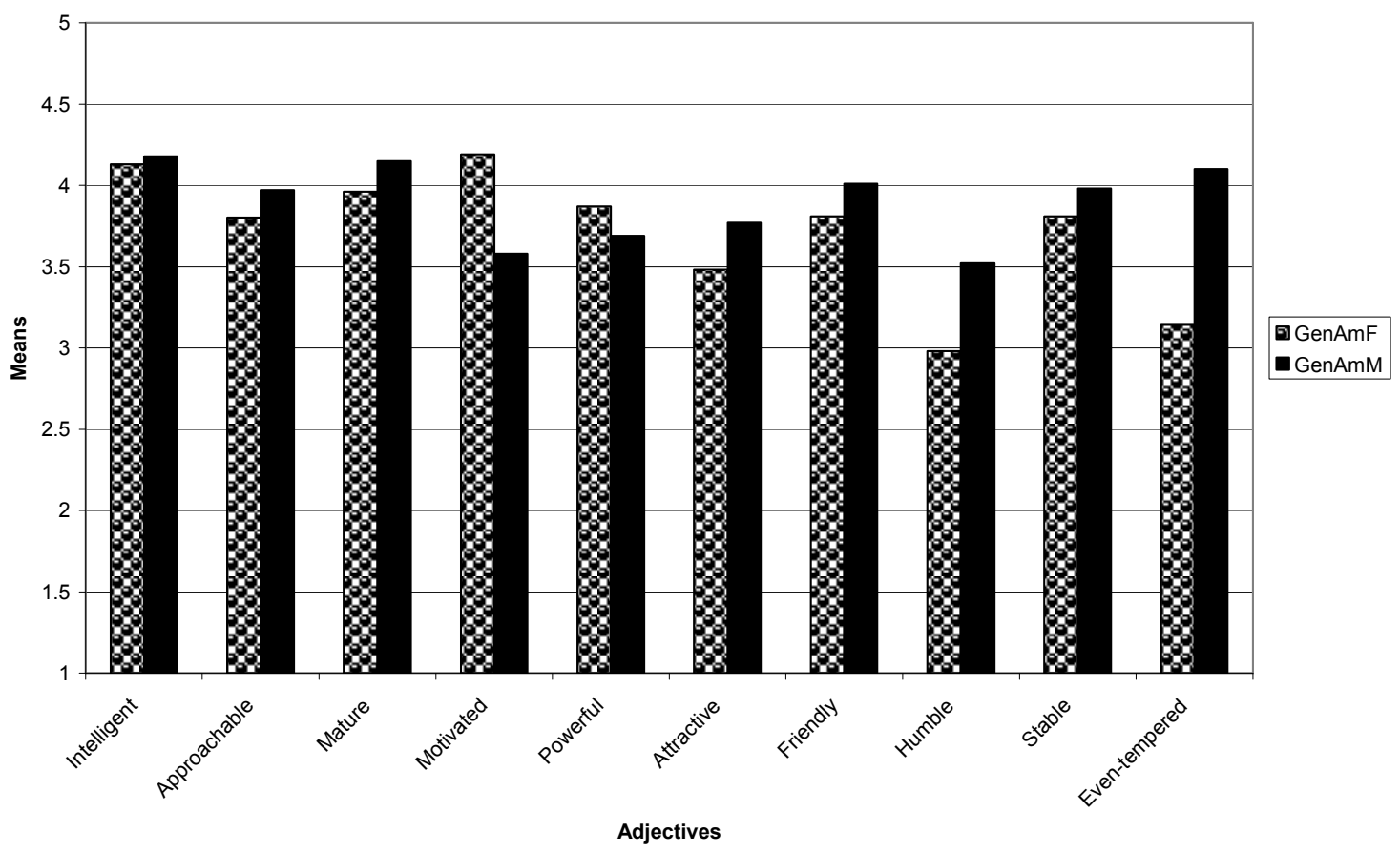


Figure 5 - Semantic Differential Means: African-American Female v. Male $(n=143)$

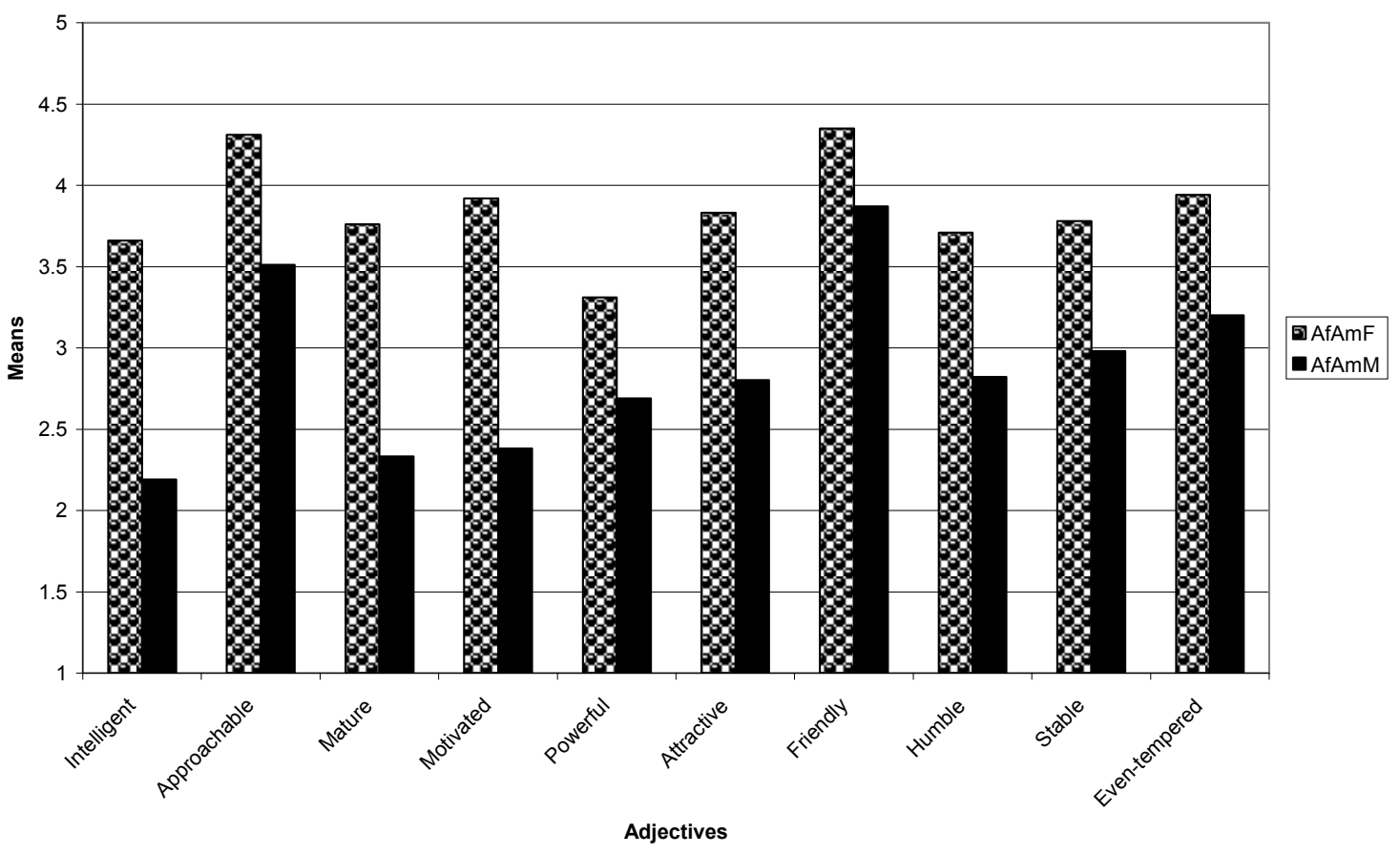


Figure 6 - Female Speaker Comparison $(n=143)$

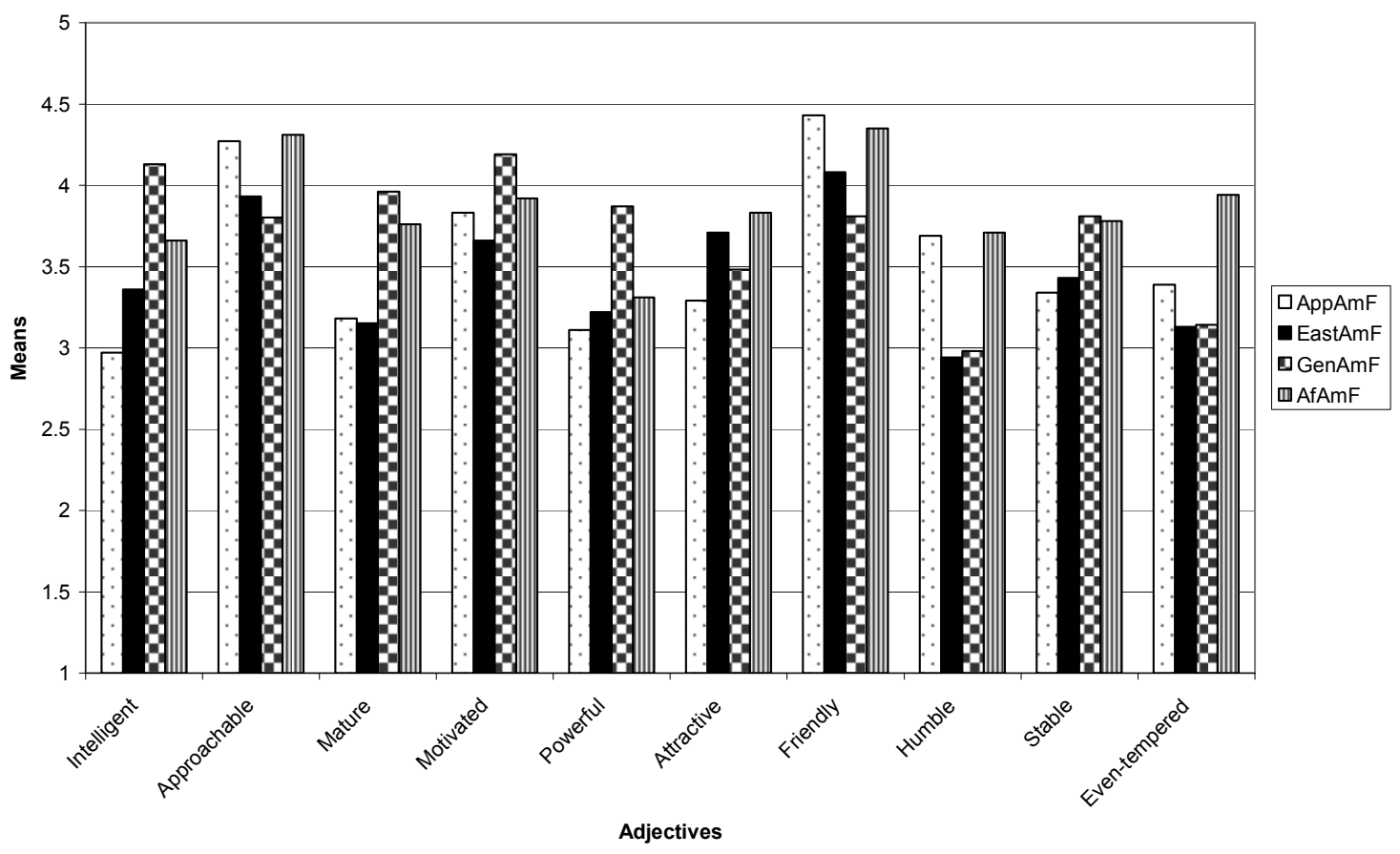


Figure 7 - Male Speaker Comparison $(n=143)$

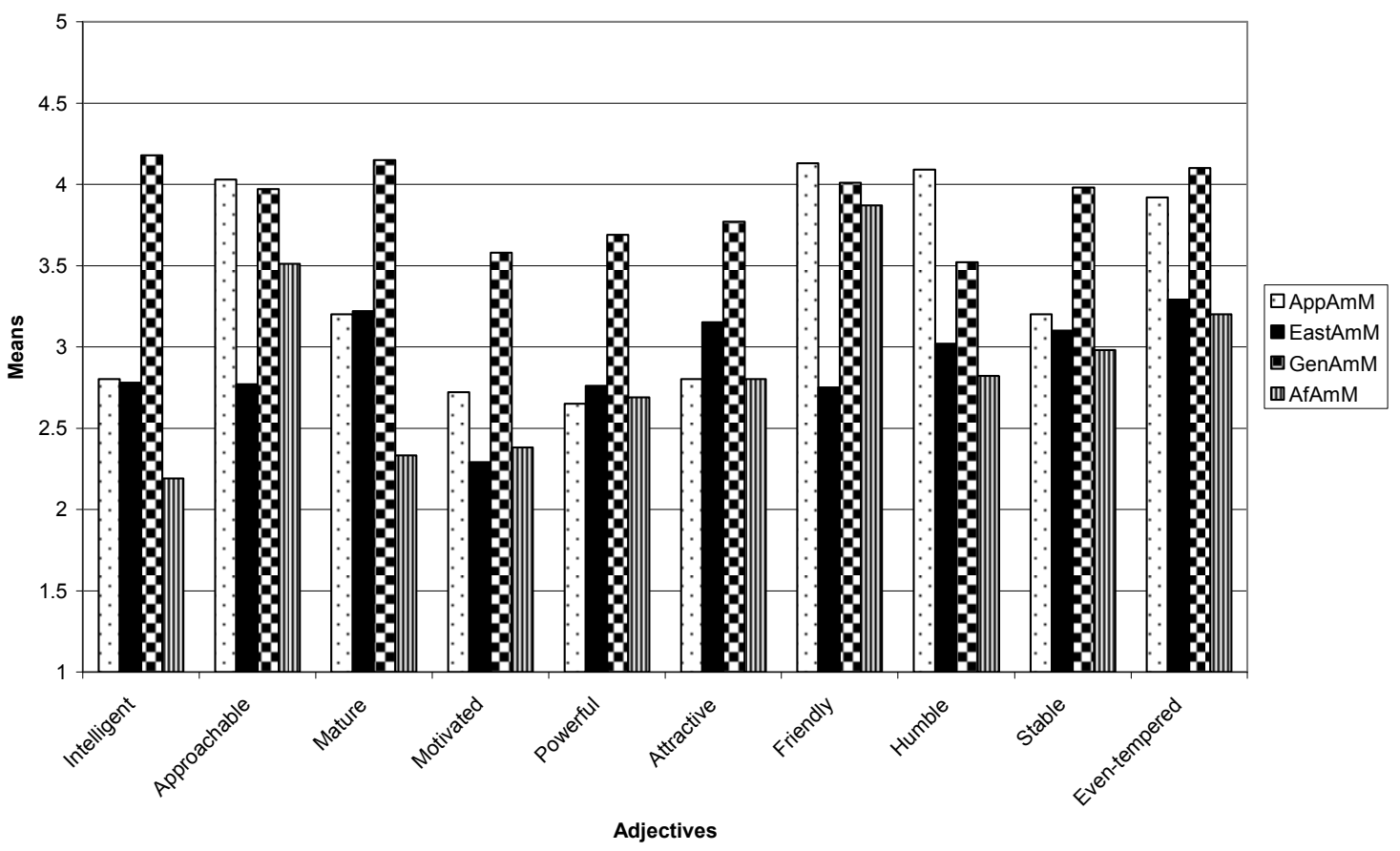




\section{Author's Note}

Writing this thesis has been such learning and growing experience for me. Many individuals have provided support along the way, be it academic or emotional. I would like to now thank those that have contributed to the successful completion of this work.

Being the only student within my program to undertake the course of completing a thesis, I relied heavily on the faculty and staff of the Speech Pathology and Audiology Department and the Educational Psychology Program at West Virginia University. I would like to acknowledge Dr. Denetta Dowler for her assistance in analyzing and revising the instrument used in this study. Also, I am grateful for the guidance and support of Dr. Richard T. Walls with regard to the statistical analysis and data presentation of the results section. Further, I am appreciative of my committee members, Dr. Lynn Cartwright, Dr. Cheryl Prichard, Dr. Dennis Ruscello, and Dr. Tekieli Koay, who were so insightful and supportive in fostering my desire for research. Dr. Carolyn P. Atkins served on paper as the Chair of my thesis committee, undergraduate advisor, Honors College advisor, and senior capstone mentor. In reality, she served as much more. Dr. Atkins also supported my graduate education by granting me two years of working under her guidance as one of four graduate teaching assistants for her public speaking course. Above all this, she was my role-model and a tremendous inspiration, as I aspire to be a professor in academia. She was an invaluable asset to my undergraduate and graduate experiences at WVU. The time she invested in me over the past five years will not be forgotten.

The support of those closest too me, who often felt the brunt of my hectic graduate school life, provided me with the will to keep striving for my dreams. I would like to thank all of my friends and students who volunteered to have their voices recorded for this project. Thank you to my fellow GTAs, Joanie, Lauren, and Tracie, for serving as my sounding board over the past two years. Last, but certainly not least, I cannot forget those who offered me unconditional love and endless encouragement at my highest and lowest points-my parents. Thank you for helping me to reach my goals. 